\title{
BMJ Open Abortion legislation, maternal healthcare, fertility, female literacy, sanitation, violence against women and maternal deaths: a natural experiment in 32 Mexican states
}

\author{
Elard Koch, ${ }^{1}$ Monique Chireau, ${ }^{2}$ Fernando Pliego, ${ }^{3}$ Joseph Stanford, ${ }^{4}$ \\ Sebastian Haddad, ${ }^{5}$ Byron Calhoun, ${ }^{6}$ Paula Aracena, ${ }^{1}$ Miguel Bravo, ${ }^{1}$ \\ Sebastián Gatica, ${ }^{1}$ John Thorp ${ }^{7,8}$
}

To cite: Koch E, Chireau M, Pliego F, et al. Abortion legislation, maternal healthcare, fertility, female literacy, sanitation, violence against women and maternal deaths: a natural experiment in 32 Mexican states. BMJ Open 2015;5:e006013. doi:10.1136/bmjopen-2014006013

- Prepublication history and additional material is available. To view please visit the journal (http://dx.doi.org/ 10.1136/bmjopen-2014006013).

Received 1 July 2014

Revised 28 November 2014 Accepted 2 December 2014

CrossMark

For numbered affiliations see end of article.

Correspondence to

Dr Elard Koch;

ekoch@melisainstitute.org

\section{ABSTRACT}

Objective: To test whether there is an association between abortion legislation and maternal mortality outcomes after controlling for other factors thought to influence maternal health.

Design: Population-based natural experiment. Setting and data sources: Official maternal mortality data from 32 federal states of Mexico between 2002 and 2011.

Main outcomes: Maternal mortality ratio (MMR), MMR with any abortive outcome $\left(M_{M} R_{A 0}\right)$ and induced abortion mortality ratio (iAMR).

Independent variables: Abortion legislation grouped as less $(n=18)$ or more permissive $(n=14)$; constitutional amendment protecting the unborn $(\mathrm{n}=17)$; skilled attendance at birth; all-abortion hospitalisation ratio; low birth weight rate; contraceptive use; total fertility rates (TFR); clean water; sanitation; female literacy rate and intimate-partner violence.

Main results: Over the 10-year period, states with less permissive abortion legislation exhibited lower MMR (38.3 vs 49.6; $p<0.001$ ), $\mathrm{MMR}_{\text {AO }}$ (2.7 vs $3.7 ; p<0.001$ ) and iAMR ( 0.9 vs $1.7 ; p<0.001)$ than more permissive states. Multivariate regression models estimating effect sizes ( $\beta$-coefficients) for mortality outcomes showed independent associations ( $p$ values between 0.001 and $0.055)$ with female literacy $(\beta=-0.061$ to -1.100$)$, skilled attendance at birth ( $\beta=-0.032$ to -0.427 ), low birth weight ( $\beta=0.149$ to 2.166 ), all-abortion hospitalisation ratio ( $\beta=-0.566$ to -0.962 ), clean water $(\beta=-0.048$ to -0.730$)$, sanitation ( $\beta=-0.052$ to -0.758 ) and intimate-partner violence ( $\beta=0.085$ to $0.755)$. TFR showed an inverse association with MMR $(\beta=-14.329)$ and $\mathrm{MMR}_{\mathrm{AO}}(\beta=-1.750)$ and a direct association with iAMR ( $\beta=1.383)$. Altogether, these factors accounted for $\left(R^{2}\right) 51-88 \%$ of the variance among states in overall mortality rates. No statistically independent effect was observed for abortion legislation, constitutional amendment or other covariates.

Conclusions: Although less permissive states exhibited consistently lower maternal mortality rates,

\section{Strengths and limitations of this study}

- To the best of our knowledge, this is the first population-based natural experiment analysing the impact of less or more permissive abortion legislation on maternal mortality outcomes in Mexico, simultaneously controlling by 10 variables thought to influence maternal health at the population level.

- In this study, relying on virtually complete, official vital statistics data, Mexican states with less permissive abortion legislation displayed lower maternal and abortion mortality ratios than states with more permissive legislation during a 10-year study period.

- In comparison to states with more permissive abortion legislation, those with less permissive legislation showed a more favourable profile in several indicators related to maternal healthcare and human development.

- Exhaustive multivariate analyses showed that observed differences in maternal mortality outcomes among states were largely explained by a combination of variables related to maternal healthcare, fertility, female literacy, intimate-partner violence against women and sanitation.

- After controlling for confounders, no evidence of deleterious or beneficial effect was found for the presence of constitutional amendments protecting the unborn over a 4-year study period.

- Since this study is based on aggregated data, the effect of analysed variables at the individual level cannot be ruled out.

this finding was not explained by abortion legislation itself. Rather, these differences were explained by other independent factors, which appeared to have a more favourable distribution in these states.

\section{INTRODUCTION}

Promoting maternal health has been a key concern for public health policymakers 
worldwide, particularly since the United Nations (UN) put forth the Millennium Development Goals (MDGs). ${ }^{1}$ As part of the fifth MDG, which focused on improving maternal health, the UN requested all member states to decrease their maternal mortality ratio $(\mathrm{MMR})^{\mathrm{i}}$ by $75 \%$ by $2015 .^{2}$

Most causes of maternal mortality are preventable, and improved access to antenatal care, ${ }^{3-5}$ as well as maternal health facilities equipped with emergency obstetric units, ${ }^{3} 4677$ and skilled attendance at childbirth, ${ }^{3} \quad 6-10$ are acknowledged public health interventions that have led to the decrease in maternal mortality worldwide. However, 1-year away from the 2015 deadline for the MDGs, the MMR has decreased less than 50\% globally, ${ }^{10-12}$ suggesting that measures taken to address maternal mortality may have been insufficient. ${ }^{11} 1314$ In this regard, although novel complementary public health or social interventions have been encouraged in support of the post-MDG agenda, ${ }^{13} 14$ these ought to be supported by data and evidence, for example, population-based natural experiments. ${ }^{15-17}$

It has been proposed that the legal status of abortion, defined as pregnancy termination by removal or expulsion of the fetus, is a factor that influences maternal health in a region, country or territory. ${ }^{18} 19$ There is a widespread perception that less permissive legislation, that is, legislation that restricts or prohibits pregnancy termination (note that 'abortion' or 'pregnancy termination' are terms used interchangeably throughout this study) leads to increased maternal mortality due to complications of clandestine, or illegal, or unsafe abortions. $^{20-22}$ Accordingly, it has also been suggested that more permissive abortion legislation would lead to a reduction in maternal deaths. ${ }^{19-21}$ However, conflicting results have been recently reported in the literature. $^{10} \quad 12 \quad 18 \quad 23-29$ For instance, evidence from settings with less permissive abortion legislation ${ }^{26}{ }^{28-31}$ suggests that other factors, such as increasing level of women's education, complimentary nutrition programmes for poor pregnant women, availability of maternal healthcare facilities, emergency obstetric units, changes in reproductive behaviour with increased family planning, and access to clean water and sanitation, may facilitate an epidemiological transition towards low maternal mortality rates in the absence of more permissive abortion legislation. ${ }^{30}$ However, this hypothesis remains to be tested or replicated at the population level in different epidemiological scenarios.

The United Mexican States (Mexico) is a federal republic comprising 32 federal territories (31 states and the Federal District, referred to as 'states' henceforth), whose population shares a common history and culture. The

${ }^{\mathrm{i}} \mathrm{MMR}$ is the quotient between the number of deaths from conditions related to or aggravated by pregnancy, childbirth or puerperium, and the number of live births during the same period of time. For purposes of comparison, this ratio is usually amplified by 10000 or 100000 observed live births.
Mexican healthcare system reached virtually universal coverage over the past century, assuring equality in access to basic healthcare for most of the population. ${ }^{32}$ Each state has its own political constitution, criminal code and abortion legislation. Moreover, while the Federal District passed a law allowing pregnancy termination on demand during the first trimester of pregnancy, several states have modified their constitutions in the opposite direction, strengthening the protection of the unborn starting at conception. ${ }^{22}$ Thus, Mexico offers a unique epidemiological scenario to test whether more or less permissive abortion legislation affects maternal mortality in a population that shares the same history and culture and that has a homogeneous healthcare system.

This study presents the results of a population-based natural experiment examining factors associated with maternal mortality in the 32 Mexican states during a period spanning 10 years (2002-2011). It analyses trends in maternal and abortion-related mortality according to differences in abortion legislation, controlling for a number of factors thought to influence maternal mortality rates.

\section{MATERIALS AND METHODS}

\section{Population data}

Official records of maternal deaths and observed live births occurring within the United Mexican States were extracted from the General Directorate of Health Information (DGIS) ${ }^{33}$ and the National Institute of Statistics, Geography, and Informatics (INEGI), ${ }^{34}$ respectively, for every state by place of residence (state where the individual used to dwell) and place of occurrence (state where the vital event took place), between 2002 and 2011 (10-year continuous period). Civil registration of vital statistics in Mexico follows international standards, has been regarded as virtually complete by the WHO, and has been included in List A-with good attribution of causes of death-along with 64 other countries. ${ }^{12}$ Since 2002, Mexico has strengthened its active epidemiological surveillance system (Intentional Search and Reclassification of Maternal Deaths) ${ }^{35}$ to correctly code maternal deaths that were initially not recognised as maternal, and to reclassify maternal deaths with erroneously attributed codes throughout the entire territory. Since this surveillance increased data reliability, 2002 was selected as the initial year for the study.

\section{Classification of maternal deaths}

Maternal deaths were identified using the 10th revision of the International Statistical Classification of Diseases and Related Health Problems (ICD-10) ${ }^{36}$ and were classified by place of residence or occurrence. Mortality ratios were directly calculated as the quotient between maternal deaths and observed live births. Three epidemiological indicators were calculated according to the classification proposed in a recent review. ${ }^{37}$ The first indicator is MMR, which considers all maternal death codes (ICD-10 codes O00-O99, A34, B20-B24 and F53) 
and is often referred to as overall maternal mortality. The second indicator is MMR with any abortive outcome $\left(\mathrm{MMR}_{\mathrm{AO}}\right)$, which considers maternal death classified following ICD-10 codes O00-O08. The third indicator is termed induced abortion mortality ratio (iAMR), which focuses only on deaths most likely associated with complications of pregnancy termination. ${ }^{37}$ Specific characteristics of this indicator allow circumvention of the problem of under-reporting of deaths from illegal abortions in countries where legal restrictions hamper the assessment of induced abortion counts and rates. First, it includes the code for medical abortion (ICD-10 code O04), which is used for the classification of deaths due to legal termination of pregnancy. Second, it also includes codes for other abortion (ICD-10 code O05), unspecified abortion (ICD-10 code O06) and failed attempted abortion (ICD-10 code O07), which are employed in Mexico and other Latin American countries for classifying deaths from induced abortion without a clear cause or when an illegal procedure is suspected. Finally, this indicator parsimoniously excludes deaths associated with well-defined pathological conditions or complications that cannot be associated with a voluntary termination of pregnancy, such as ectopic pregnancy (ICD-10 code O00), hydatidiform mole (ICD-10 code O01), other abnormal products of conception (ICD-10 code O02), spontaneous abortion (ICD-10 code O03), and complications following abortion and ectopic and molar pregnancy (ICD-10 code O08). ${ }^{37}$

\section{Abortion legislation}

Criminal legislation for each state was reviewed and extracted from the National Office for the Judiciary of the Mexican government. ${ }^{38}$ The revision of current criminal codes of each Mexican state is summarised in table 1 . In practical terms, all 32 states provide criminal exemptions from prosecution for abortions performed in case of rape, 29 states provide criminal exemptions in imprudent or accidental cases, 25 states provide exemptions when the life or health of the mother is at risk, 10 states do so in cases of artificial insemination without consent, 1 state does so for social causes and 14 states do so in cases of genetic or congenital fetal conditions resulting in an individual with serious physical or mental deficiencies. In addition, in 2007, the Federal District passed a law allowing legal pregnancy termination on request up to the 12th week of pregnancy. ${ }^{39}$ In exploratory analyses, segregating states by the number of exemptions provided in criminal codes did not result in detectable differences in sensitivity analyses, with the exception of abortion allowed by genetic or congenital fetal malformations. The remaining seven exemptions were distributed differentially in almost every state or very few states, thus offering no discrimination potential. Therefore, to differentiate between states with more or less permissive abortion legislation in subsequent statistical analyses, states allowing pregnancy termination due to serious genetic or congenital conditions were considered more permissive (14 states), while the remaining states were considered less permissive (18 states).

\section{Political constitution amendments}

Data on amendments to the political constitution of each state were extracted from the National Office for the Judiciary of the Mexican government. ${ }^{38}$ Specifically, constitutional amendments specifying an explicit protection of the unborn starting at conception were tracked in time and form by examining the political constitution of each state. A number of states amended their constitutions to this effect almost immediately after the legalisation of pregnancy termination on request in the Federal District in April of 2007. ${ }^{39}$ These progressive changes required a dynamic allocation of states according to the date of enactment or derogation of the amendment during the 4-year period of analysis between 2008 and 2011 (see online supplementary figure S1). In addition to the state of Chihuahua, which amended its constitution in 1994, 16 other states had enacted these amendments by the end of 2011. In subsequent statistical analysis, a direct comparison of maternal and abortion-related deaths was carried out between groups of states with amendment (17 states) and without an amendment (15 states). In addition, subanalyses that discriminated maternal and abortion-related mortality between the Federal District and other states were also conducted.

\section{Independent variables}

Other independent variables considered were percentage of the population with access to clean water ('clean water'), sanitary sewer coverage ('sanitation'), average total fertility rate between 2002 and 2011 ('TFR'), percentage of contraceptive use by married or in-union female population of fertile age ('contraceptive use'), percentage of skilled attendance at birth ('skilled attendance at birth'), low birth weight rate ('low birth weight'), female literacy rate ('female literacy'), all-abortion hospitalisation ratio and percentage of intimate-partner violence against married or in-union women over the past year ('intimate-partner violence'). Operational definitions, their significance for epidemiological studies (for subsequent interpretation), measurement scales and data sources for these variables are detailed in online supplementary table S1.

\section{Statistical analyses}

Parallel time series were constructed between 2002 and 2011 for maternal deaths and registered live births according to abortion legislation. Trends for MMR, $\mathrm{MMR}_{\mathrm{AO}}$ and iAMR per 100000 live births were directly calculated for every federal state and were evaluated over time by occurrence and residence using an autoregressive integrated moving average (ARIMA) model. The complete time series data used in this study are presented in online supplementary tables S2-S15. In each ARIMA model, the $\beta$-coefficient represents 
Table 1 Current abortion legislations based on criminal exemptions from prosecution of abortion in 32 Mexican states exhibiting a more $(\mathrm{m})$ or less (I) permissive abortion legislation

\begin{tabular}{|c|c|c|c|c|c|c|c|c|}
\hline & Rape & $\begin{array}{l}\text { Imprudential } \\
\text { conduct }\end{array}$ & $\begin{array}{l}\text { Risk to the } \\
\text { life of the } \\
\text { mother }\end{array}$ & $\begin{array}{l}\text { Genetic or } \\
\text { congenital } \\
\text { malformation }\end{array}$ & $\begin{array}{l}\text { Serious risk } \\
\text { to the health } \\
\text { of the mother }\end{array}$ & $\begin{array}{l}\text { Artificial } \\
\text { insemination } \\
\text { without consent }\end{array}$ & $\begin{array}{l}\text { Economic } \\
\text { or social } \\
\text { reasons }\end{array}$ & $\begin{array}{l}\text { On } \\
\text { demand }\end{array}$ \\
\hline Aguascalientes (I) & $\checkmark$ & $\checkmark$ & $\checkmark$ & & & & & \\
\hline Baja California (I) & $\checkmark$ & $\checkmark$ & $\checkmark$ & & & $\checkmark$ & & \\
\hline Baja California Sur (m) & $\checkmark$ & $\checkmark$ & $\checkmark$ & $\checkmark$ & $\checkmark$ & $\checkmark$ & & \\
\hline Campeche (I) & $d$ & 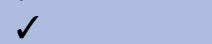 & & & 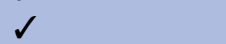 & & & \\
\hline Coahuila (m) & $\checkmark$ & $\checkmark$ & $\checkmark$ & $\checkmark$ & & & & \\
\hline Colima (m) & $\checkmark$ & $\checkmark$ & $\checkmark$ & $\checkmark$ & & $\checkmark$ & & \\
\hline Chiapas (m) & $\checkmark$ & & $\checkmark$ & $\checkmark$ & & & & \\
\hline Chihuahua (I) & $\checkmark$ & $\checkmark$ & & & $\checkmark$ & $\checkmark$ & & \\
\hline Distrito Federal $(\mathrm{m})$ & $\checkmark$ & $\checkmark$ & & $\checkmark$ & $\checkmark$ & $\checkmark$ & & $\checkmark$ \\
\hline Durango (I) & $\checkmark$ & $\checkmark$ & $\checkmark$ & & & & & \\
\hline Guanajuato (I) & $\checkmark$ & $\checkmark$ & & & & & & \\
\hline Guerrero $(m)$ & $\checkmark$ & $\checkmark$ & & $\checkmark$ & & $\checkmark$ & & \\
\hline Hidalgo $(\mathrm{m})$ & $\checkmark$ & $\checkmark$ & & $\checkmark$ & $\checkmark$ & & & \\
\hline Jalisco (I) & $\checkmark$ & $\checkmark$ & $\checkmark$ & & $\checkmark$ & & & \\
\hline México (m) & $\checkmark$ & $\checkmark$ & $\checkmark$ & $\checkmark$ & & & & \\
\hline Michoacán (I) & $\checkmark$ & 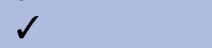 & $\checkmark$ & & $\checkmark$ & & & \\
\hline Morelos (m) & $\checkmark$ & $\checkmark$ & $\checkmark$ & $\checkmark$ & & $\checkmark$ & & \\
\hline Nayarit (I) & $\checkmark$ & $\checkmark$ & $\checkmark$ & & $\checkmark$ & & & \\
\hline Nuevo León (I) & $\checkmark$ & & $\checkmark$ & & $\checkmark$ & & & \\
\hline Oaxaca $(m)$ & 1 & $\checkmark$ & 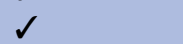 & $\checkmark$ & & & & \\
\hline Puebla (m) & $\checkmark$ & $\checkmark$ & $\checkmark$ & $\checkmark$ & & & & \\
\hline Querétaro (I) & $\checkmark$ & $\checkmark$ & & & & & & \\
\hline Quintana Roo (m) & $\checkmark$ & $\checkmark$ & $\checkmark$ & $\checkmark$ & & & & \\
\hline San Luis Potosí (I) & 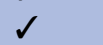 & 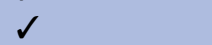 & 2 & & & $\checkmark$ & & \\
\hline Sinaloa (I) & $\checkmark$ & $\checkmark$ & $d$ & & & & & \\
\hline Sonora (I) & $\checkmark$ & $\checkmark$ & $\checkmark$ & & & & & \\
\hline Tabasco (I) & $\checkmark$ & & $\checkmark$ & & & $\checkmark$ & & \\
\hline Tamaulipas (I) & $\checkmark$ & $\checkmark$ & $\checkmark$ & & $\checkmark$ & & & \\
\hline Tlaxcala (I) & $s$ & $\checkmark$ & $d$ & & $\checkmark$ & & & \\
\hline Veracruz (m) & $\checkmark$ & $\checkmark$ & $\checkmark$ & $\checkmark$ & & $\checkmark$ & & \\
\hline Yucatán (m) & $\checkmark$ & $\checkmark$ & $\checkmark$ & $\checkmark$ & & & $\checkmark$ & \\
\hline Zacatecas (I) & $\checkmark$ & 2 & 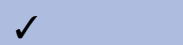 & & $\checkmark$ & & & \\
\hline Total & 32 & 29 & 25 & 14 & 12 & 10 & 1 & 1 \\
\hline
\end{tabular}


the average change per year of the mortality outcome and the $\mathrm{p}$ for trend indicates the statistical significance of the overall trend. Average mortality ratios over the total time period were also computed and directly matched using the Z-test. The proportion (\%) of induced abortion-related deaths (ie, proportion of deaths due to pregnancy termination over the total number of maternal deaths) was also computed and comparatively analysed.

The Kolmogorov-Smirnov test was utilised to assess the normal distribution assumption. Multiple regression was used to estimate the effect size of independent variables on average mortality ratios (MMR, $\mathrm{MMR}_{\mathrm{AO}}$ and iAMR) and explain the variance among the 32 states controlling for other factors. Owing to the potential collinearity related to the high number of predictors, a Pearson correlation matrix was used to quantify the magnitude of bivariate linear associations among all independent variables. Pearson coefficients $(r) \geq 0.70$ were considered to suggest collinearity. Exploratory models were conducted to assess collinearity using the variance inflation factor (VIF) ${ }^{40}$ The covariates selected for inclusion in explanatory regression models were analysed using the backward stepwise elimination method based on $\mathrm{p}$ values of 0.05 and 0.059 as criteria of entry and removal, respectively. $\beta$-Coefficients with $95 \%$ CIs were computed to assess the effect size of each predictor on the MMR, $\mathrm{MMR}_{\mathrm{AO}}$ and iAMR, and the change in the $\mathrm{R}^{2}$ was used to determine the final models with maximal goodness-of-fit, minimal number of explanatory variables and minimal collinearity. To examine the stability of $\beta$-coefficients and obtain unbiased effect sizes, two panels of multivariate explanatory models were considered for each mortality outcome, based on diagnostic regression refinement of residual statistics, by eliminating the presence of outliers (higher than 2 SDs of predicted mortality outcome) when presented.

\section{RESULTS}

\section{Abortion legislation and maternal mortality}

During the 10-year study period, there were 11649 maternal deaths and 26089498 live births in Mexico, corresponding to an MMR of 44.7/100 000 live births. The MMR in 2002 was 48.6, decreasing to 37.7/100 000 live births in 2011, representing a total reduction of $22.4 \%$. In the same period, there were 855 deaths with abortive outcome, representing an $\mathrm{MMR}_{\mathrm{AO}}$ of 3.28/100 000 live births. This outcome displayed a 20.5\% decrease between 2002 (3.61/100 000 live births) and 2011 (2.87/100 000 live births). For this period, there were 352 deaths associated with ICD-10 codes O04 through O07, representing an iAMR of 1.35/100 000 live births. This outcome decreased by $29.5 \%$ between 2002 and 2011, from 1.49 to 1.05 deaths per 100000 live births.

Regardless of where the vital event took place, MMR, $\mathrm{MMR}_{\mathrm{AO}}$, iAMR and the proportion of induced abortion- related deaths between 2002 and 2011 were lower in the group of states with less permissive abortion legislation (figures 1 and 2). Table 2 summarises the linear trends of all three mortality outcomes in each group of states and the entire Mexican country for the study period, by residence and occurrence, respectively. In each group, the $\beta$-coefficient represents the average change per year of the mortality outcome and the $\mathrm{p}$ for trend indicates the statistical significance of the overall trend. The group of states with less permissive abortion legislation showed apparently stable trends for MMR, MMR $\mathrm{AO}_{\mathrm{AO}}$ and iAMR during the decade analysed. The group of states with more permissive abortion legislation displayed decreasing trends for MMR, MMR ${ }_{\mathrm{AO}}$ and $\mathrm{iAMR}$, narrowing the gap between the two groups by 2011, but still exhibited statistically significant differences (eg, MMR of 40.9 vs 33.5 per 100000 live births for more permissive vs less permissive states, $\mathrm{Z}=3.04$, rate $\mathrm{ratio}=0.82$, $\mathrm{p}=0.002)$. State-by-state trends and estimated $\beta$-coefficients for the time series of MMR, $M_{M R}$ and iAMR are presented by residence (see online supplementary tables S10-S12) and by occurrence (see online supplementary tables S13-S15).

Figure 3 illustrates in a blue scale the geographic distribution of average MMR (top panel) and iAMR (bottom panel) for the 10-year period in territories of the whole country. The differences in average mortality outcomes between groups are summarised in table 3 . The average MMR for the 10-year period by place of residence and occurrence in the group of states with less permissive legislation was $23 \%$ and $21 \%$ lower, respectively, than the value in the group of states with more permissive legislation. Similarly, the group of states with less permissive abortion legislation showed an average $\mathrm{MMR}_{\mathrm{AO}}$ by place of residence and occurrence that was $27 \%$ and $24 \%$ lower, respectively, than states with more permissive legislation. The highest difference between both groups was for the average iAMR, which was $47 \%$ lower in states with less permissive legislation, for analyses by residence and occurrence. Finally, the average proportion of induced abortion-related deaths over the total number of maternal deaths by place of residence was $2.4 \%$ and $3.4 \%(p=0.002)$ in the groups of states with less and more permissive abortion legislation, respectively; by place of occurrence, the figures were $2.3 \%$ and $3.5 \%(p<0.001)$, respectively. Excluding the Federal District from the group of states with more permissive abortion legislation did not significantly modify these results.

\section{Constitutional amendments and maternal mortality}

Regardless of where the vital event took place, iAMR and the proportion of induced abortion-related deaths between 2008 and 2011—but not MMR and $\mathrm{MMR}_{\mathrm{AO}}$, for which rates overlapped-were apparently higher in the group of states that did not amend their constitutions (figures 4 and 5); however, these differences were not statistically significant for the 4-year period ( $p$ for 


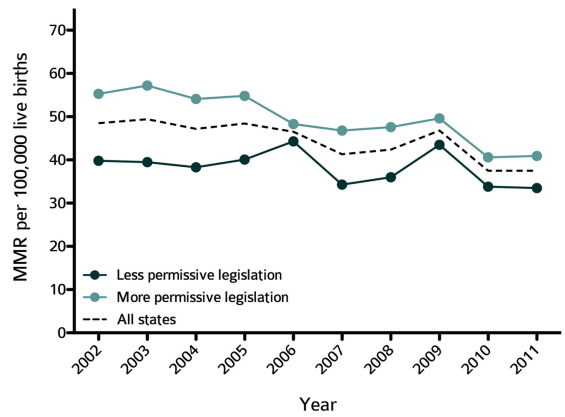

Indicators by place of residence
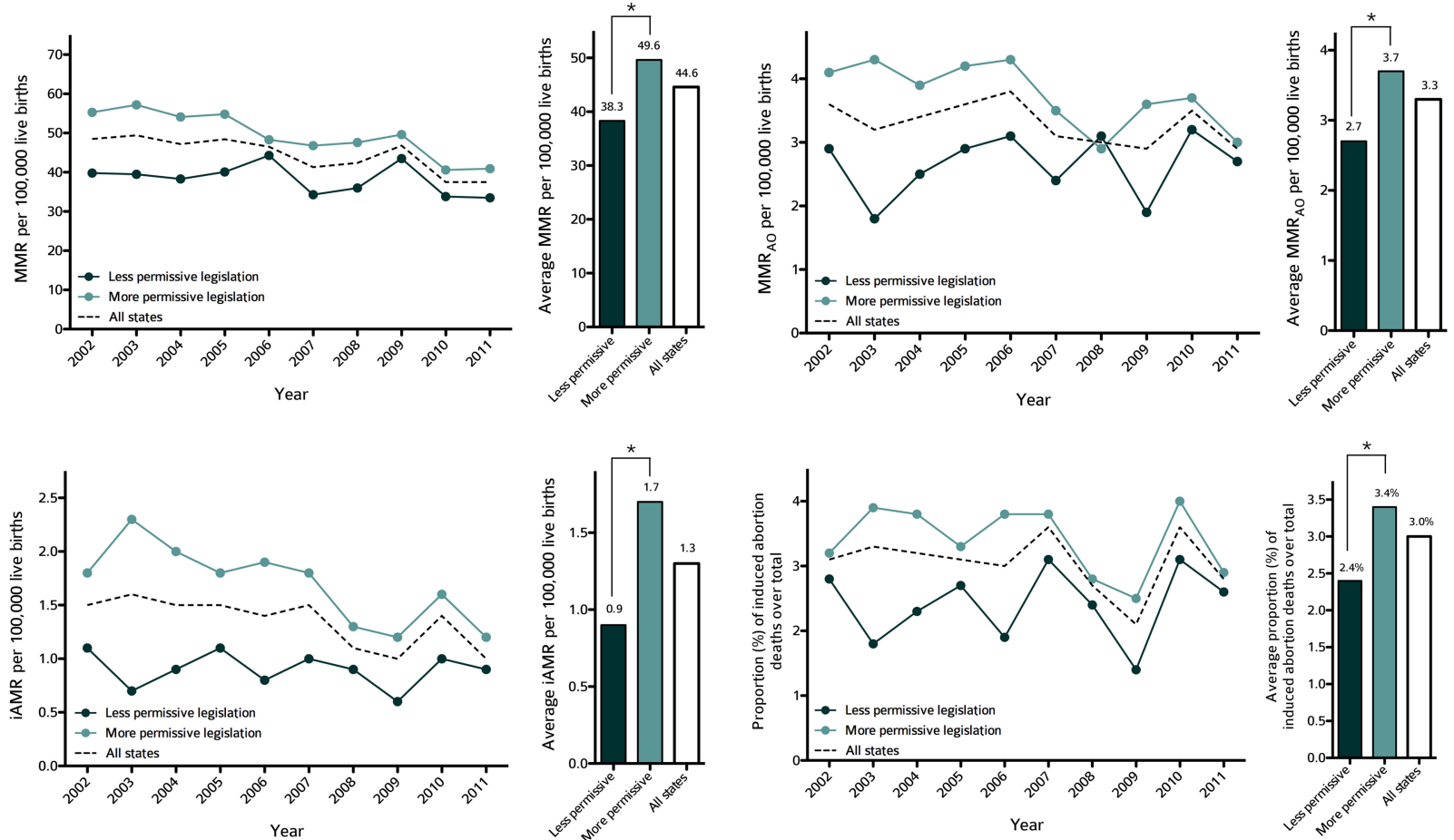

Figure 1 Mortality ratios and the proportion of abortion-related deaths by place of residence in states with less and more

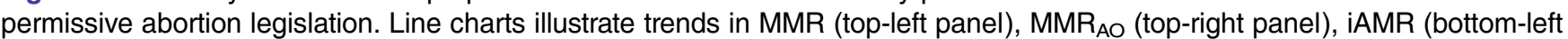
panel) and the proportion of abortion-related deaths (bottom-right panel) by place of residence between 2002 and 2011 in Mexican states, grouped as with less permissive (in dark green) or more permissive (in cyan) in terms of abortion legislation in their criminal code (see Materials and methods). For comparison, trends for the whole Mexican country (all states) are depicted as dotted lines. Bar charts show average ratios and proportions of abortion-related deaths for each group (dark green and cyan bars, respectively), and the whole Mexican country (hollow bars). ${ }^{*} p<0.05$ using Z-test. iAMR, induced abortion mortality ratio; MMR, maternal mortality ratio; $\mathrm{MMR}_{\mathrm{AO}}, \mathrm{MMR}$ with an abortive outcome.

trend $=0.670)$. The differences in average mortality outcomes between groups are summarised in table 4 . Differences were observed in the average iAMR and proportion of induced abortion-related deaths for the total period of 4 years. The average iAMR either by place of residence or by place of occurrence in states with constitutional amendments was $31 \%$ lower than the value in states without amendments. The average proportion of induced abortion-related deaths over the total number of maternal deaths by place of residence was $2.1 \%$ in states with amendment and $3.1 \%$ in states without amendment $(\mathrm{p}=0.041)$; by place of occurrence, the figures were $2.2 \%$ in states with amendment and $3.2 \%$ in states without amendment $(\mathrm{p}=0.048)$.

After removing the Federal District from the group of states without constitutional amendments, differences were observed in the average $\mathrm{MMR}$ and $\mathrm{MMR}_{\mathrm{AO}}$ between the groups, but only in the analysis of mortality by place of occurrence (figures 5 and 7). The Federal District showed a higher average $\mathrm{MMR}$ and $\mathrm{MMR}_{\mathrm{AO}}$ by place of occurrence than did the group of states with constitutional amendments. In addition, removal of the Federal District from the group of states without constitutional amendments abolished the differences found in the average iAMR and proportion of induced abortionrelated deaths by place of occurrence (figures 5 and 7), but not by place of residence (figures 4 and 6) between the latter group and the group of states with the amendment. Results for each mortality outcome are compared in table 4.

\section{Primary explanatory regression models}

Table 5 shows data for all covariates for each Mexican state, and includes the results from tests of normal distribution for each variable. Simple regression models illustrating the initial effect size ( $\beta$-coefficient) for each covariate, including abortion legislation and constitutional amendment, are presented in table 6 . For instance, less permissive abortion legislation was associated with an average decrease of 7.31/100 000 live births for MMR.

Exploratory regression analyses showed collinearity between independent variables. A full model introducing all independent variables simultaneously (not shown) showed VIF values between 1.537 and 9.082. In particular, five of the nine independent variables showed VIF values higher than 4.0 (clean water, sanitation, TFR, contraceptive use and female literacy), suggesting the presence of multicollinearity. A correlation matrix 


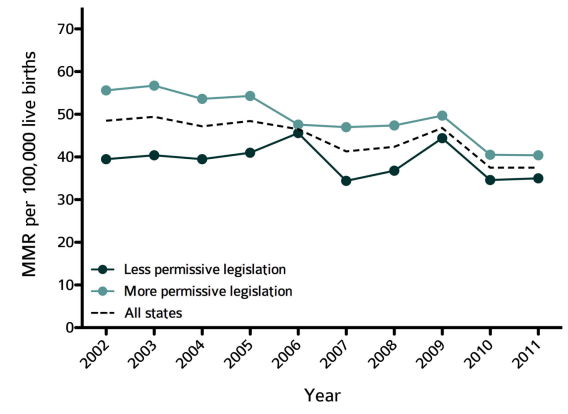

Indicators by place of occurrence
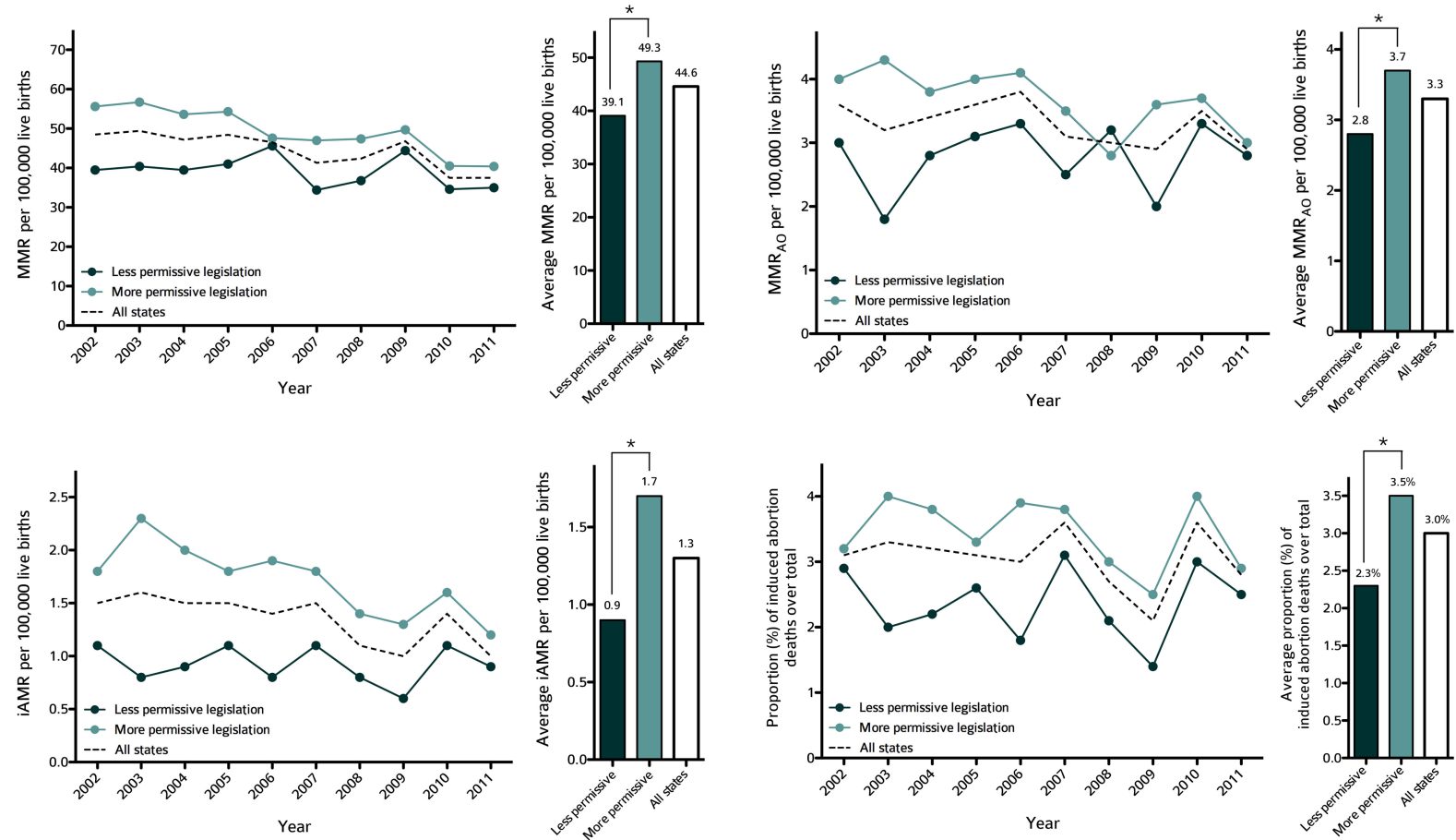

Figure 2 Mortality ratios and the proportion of abortion-related deaths by place of occurrence in states with less and more

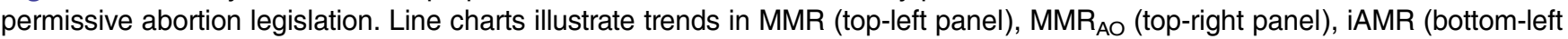
panel) and the proportion of abortion-related deaths (bottom-right panel) by place of occurrence between 2002 and 2011 in Mexican states, grouped as with less permissive (in dark green) or more permissive (in cyan) in terms of abortion legislation in their criminal code (see Materials and methods). For comparison, trends for the whole Mexican country (all states) are depicted as dotted lines. Bar charts show average ratios and proportions of abortion-related deaths for each group (dark green and cyan bars, respectively), and the whole Mexican country (hollow bars). ${ }^{*} p<0.05$ using Z-test. iAMR, induced abortion mortality ratio; MMR, maternal mortality ratio; $M_{\mathrm{AO}}, \mathrm{MMR}$ with abortive outcome.

showed a high inverse correlation between TFR and contraceptive use $(\mathrm{r}=-0.76 ; \mathrm{p}<0.001)$, suggesting that these variables were interchangeable. Other pairs of variables with high Pearson coefficients were clean water with sanitation $(\mathrm{r}=0.79 ; \mathrm{p}<0.001)$, and female literacy with clean water $(\mathrm{r}=0.85 ; \mathrm{p}<0.001)$ or with sanitation $(\mathrm{r}=0.86$; $\mathrm{p}<0.001)$. Thus, contraceptive use and female literacy were selected for primary explanatory models. When TFR, clean water and sanitation were excluded, VIF substantially decreased to values between 1.087 and 3.338 .

Table 7 shows the multivariate explanatory models for MMR, $\mathrm{MMR}_{\mathrm{AO}}$ and $\mathrm{iAMR}$ using the backward stepwise elimination method and after statistical refinement. Models before refinement are presented in online supplementary table S16. In general, an increase in $\beta$-coefficients and $\mathrm{R}^{2}$ was observed after statistical refinement. In every multivariate regression model, each $\beta$-coefficient represents the average change in the outcome of interest (ie, MMR, MMR unit of change in each independent variable (eg, \% skilled attendance at birth, \% female literacy, \% low birth weight, etc) controlling for all other covariates in the model, and $\mathrm{R}^{2}$ represents the proportion of the total variability in the mortality outcome explained by the full model. The refined model for MMR excluded two states as outliers (Chihuahua and Nueva León) and identified four predictors: female literacy, low birth weight, all-abortion hospitalisation ratio and intimate-partner violence. These variables accounted for $69 \%$ of observed differences in MMR among states $\left(\mathrm{R}^{2}\right.$ for model). The contribution of each variable for explaining the variance of MMR among states (partial $\mathrm{R}^{2}$ ) was $50.9 \%, 15.1 \%$, $4.4 \%$ and $2.8 \%$, respectively. No independent effect was observed for abortion legislation, constitutional amendment or other covariates. Regarding $\mathrm{MMR}_{\mathrm{AO}}$, the refined model excluded two states as outliers (Aguascalientes and Nayarit), identifying three predictors: female literacy, low birth weight and skilled attendance at birth. These variables accounted for $62 \%\left(\mathrm{R}^{2}\right.$ for model 0.624; $\mathrm{p}<0.001)$ of observed differences in $\mathrm{MMR}_{\mathrm{AO}}$ among states. The individual contributions of each factor for explaining the variance of $\mathrm{MMR}_{\mathrm{AO}}$ among states were $11.9 \%, 40.2 \%$ and $14.2 \%$, respectively. No independent effect was observed for abortion legislation, constitutional amendment or other covariates. Finally, regarding iAMR, the refined model excluded four states as outliers (Aguascalientes, Durango, Sonora and Tlaxcala), identifying three predictors: female literacy, low birth weight, skilled attendance at birth and intimate-partner violence. These variables accounted for $78 \%\left(\mathrm{R}^{2}\right.$ for model 0.777 ; 
Table 2 Average change per year in different maternal mortality outcomes by place of residence and occurrence in groups of Mexican states with more or less permissive abortion legislation and the entire country (2002-2011) based on ARIMA models

\begin{tabular}{|c|c|c|c|c|c|c|c|c|c|}
\hline & \multicolumn{3}{|l|}{ MMR } & \multicolumn{3}{|l|}{$\mathrm{MMR}_{\mathrm{AO}}$} & \multicolumn{3}{|l|}{ iAMR } \\
\hline & $\overline{\boldsymbol{\beta}^{*}}$ & SE† & pł & $\overline{\boldsymbol{\beta}^{*}}$ & SE† & $\mathbf{p} \neq$ & $\overline{\boldsymbol{\beta}^{*}}$ & SE† & $\mathrm{p} \ddagger$ \\
\hline \multicolumn{10}{|l|}{ By place of residence } \\
\hline Less permissive states (18) & -0.563 & 0.405 & 0.202 & 0.030 & 0.057 & 0.615 & -0.010 & 0.019 & 0.619 \\
\hline More permissive states (14) & -1.766 & 0.276 & $<0.001$ & -0.123 & 0.040 & 0.016 & -0.096 & 0.025 & 0.005 \\
\hline United Mexican States (32) & -1.258 & 0.286 & 0.002 & -0.056 & 0.032 & 0.121 & -0.058 & 0.017 & 0.010 \\
\hline \multicolumn{10}{|l|}{ By place of occurrence } \\
\hline Less permissive states (18) & -0.487 & 0.428 & 0.288 & 0.025 & 0.061 & 0.688 & -0.011 & 0.020 & 0.602 \\
\hline More permissive states (14) & -1.764 & 0.275 & $<0.001$ & -0.112 & 0.040 & 0.022 & -0.092 & 0.023 & 0.004 \\
\hline United Mexican States (32) & -1.258 & 0.286 & 0.002 & -0.056 & 0.032 & 0.121 & -0.058 & 0.017 & 0.010 \\
\hline
\end{tabular}

${ }^{*} \beta$-coefficient representing the average change per year for trend of MMR per 100000 live births between 2002 and 2011.

†SE for $\beta$-coefficient obtained between 2002 and 2011 with ARIMA.

fp Value for trend between 2002 and 2011.

ARIMA, Autoregressive Integrated Moving Average; iAMR, induced abortion mortality ratio; MMR, maternal mortality ratio MMR $\mathrm{AO}_{\mathrm{O}}$, MMR with any abortive outcome.

$\mathrm{p}<0.001)$ of observed differences in iAMR among states. The relative contributions of these variables for explaining the variance of iAMR ( partial $\mathrm{R}^{2}$ ) among states were
$39.9 \%, 19.1 \%, 14.8 \%$ and $7.2 \%$, respectively. No statistically independent effect was observed for abortion legislation, constitutional amendment or other covariates.
Figure 3 Average mortality ratios in states with more or less permissive abortion legislation between 2002 and 2011. Political maps of Mexican states are shown for average MMR (top panel) and average iAMR (bottom panel) for the 2002-2011 period, indicating whether they exhibit less (orange dots) or more (yellow dots) permissive abortion legislation, in terms of their criminal code (see Materials and methods). Increasing blue colour indicates an increase in MMR or iAMR on a quintile or quartile scales (see the legend of each panel). Ag., Aguascalientes; Co., Colima; FD., Federal District; IAMR, induced abortion mortality ratio; MMR, maternal mortality ratio; Mo., Morelos; TI., Tlaxcala.
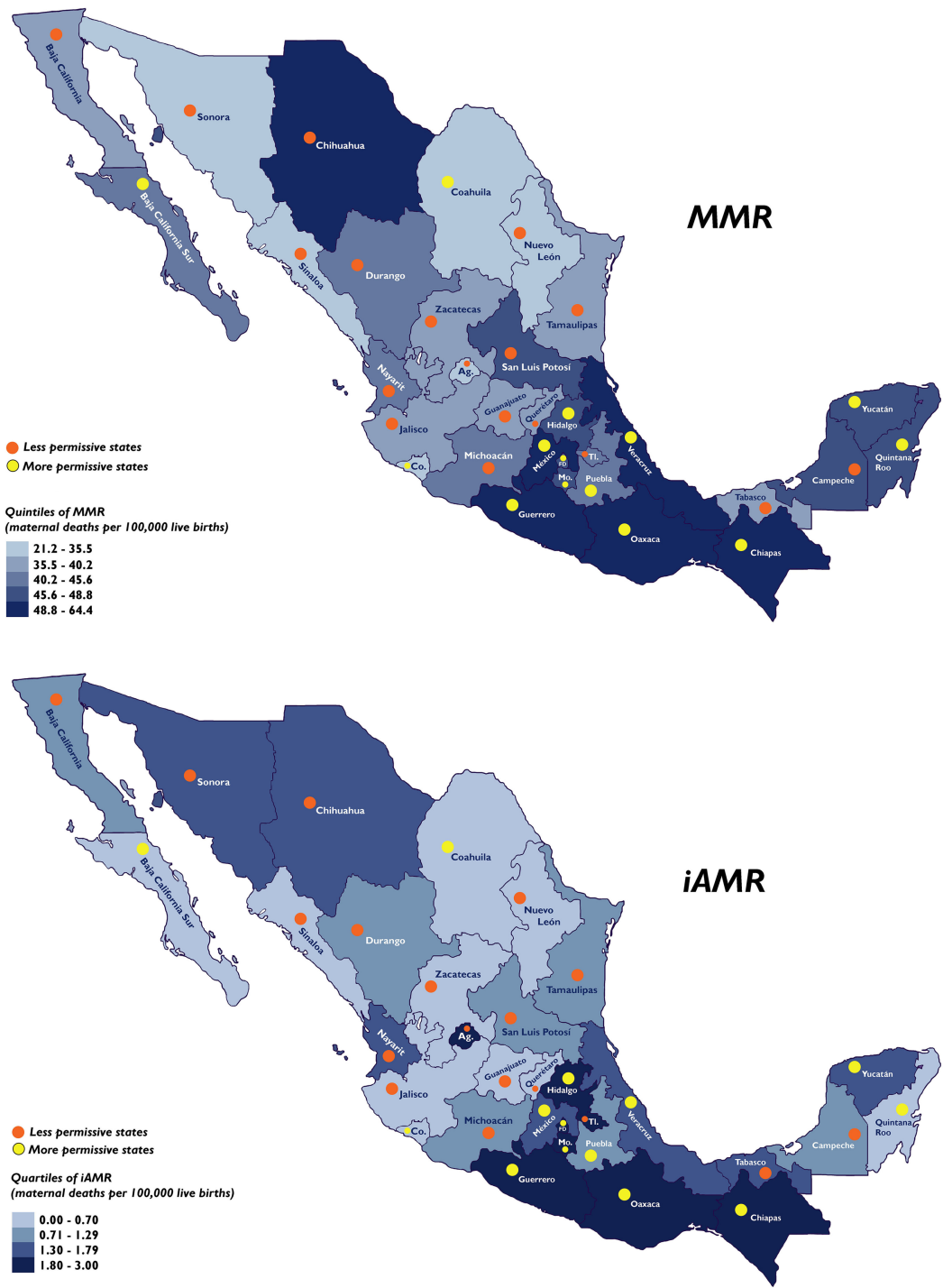
Table 3 Comparative analysis of average mortality outcomes by residence and occurrence for groups of Mexican states exhibiting a more or less permissive abortion legislation, 2002-2011

\begin{tabular}{|c|c|c|c|c|c|}
\hline Indicator & & Less permissive & More permissive & Rate ratio* & pt \\
\hline \multirow{2}{*}{ MMR } & By residence & 38.3 & 49.6 & 0.7722 & $<0.001$ \\
\hline & By occurrence & 39.1 & 49.3 & 0.7922 & $<0.001$ \\
\hline \multirow[t]{2}{*}{$\mathrm{MMR}_{\mathrm{AO}}$} & By residence & 2.7 & 3.7 & 0.7110 & $<0.001$ \\
\hline & By occurrence & 2.8 & 3.7 & 0.7491 & $<0.001$ \\
\hline \multirow[t]{2}{*}{ iAMR } & By residence & 0.9 & 1.7 & 0.5358 & $<0.001$ \\
\hline & By occurrence & 0.9 & 1.7 & 0.5337 & $<0.001$ \\
\hline \multirow{2}{*}{$\begin{array}{l}\text { Proportion of induced } \\
\text { abortion-related deaths }\end{array}$} & By residence & $2.4 \%$ & $3.4 \%$ & $\ddagger$ & $<0.001$ \\
\hline & By occurrence & $2.3 \%$ & $3.5 \%$ & $\ddagger$ & $<0.001$ \\
\hline $\begin{array}{l}\text { *Z-test rate ratio. } \\
\text { tZ-test } p \text { value. } \\
\text { fNot applicable. } \\
\text { iA }\end{array}$ & 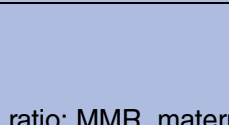 & 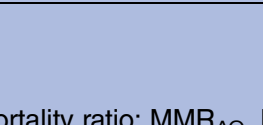 & 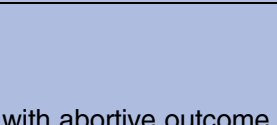 & & \\
\hline
\end{tabular}

\section{Alternative explanatory regression models}

Alternative multivariate regression models considering variables initially excluded by collinearity are summarised in table 8. For instance, in the first of these alternative models, female literacy was exchanged with clean water (ie, female literacy was excluded from the model, whereas clean water was included). After regression refinement, four factors were identified as independent explanatory variables for the MMR: clean water, low birth weight, all-abortion hospitalisation ratio and intimatepartner violence. These variables accounted for $88 \%\left(\mathrm{R}^{2}\right.$ for model $0.886 ; \mathrm{p}<0.001$ ) of observed differences in MMR among states. The individual contribution (partial $\mathrm{R}^{2}$ ) of each factor for explaining the variance of MMR among states was $64.7 \%, 22.0 \%, 1.9 \%$ and $1.7 \%$, respectively. Regarding $\mathrm{MMR}_{\mathrm{AO}}$, the model identified skilled attendance at birth and low birth weight as independent predictors, accounting for $42 \%$ of the difference among

\section{Indicators by place of residence}
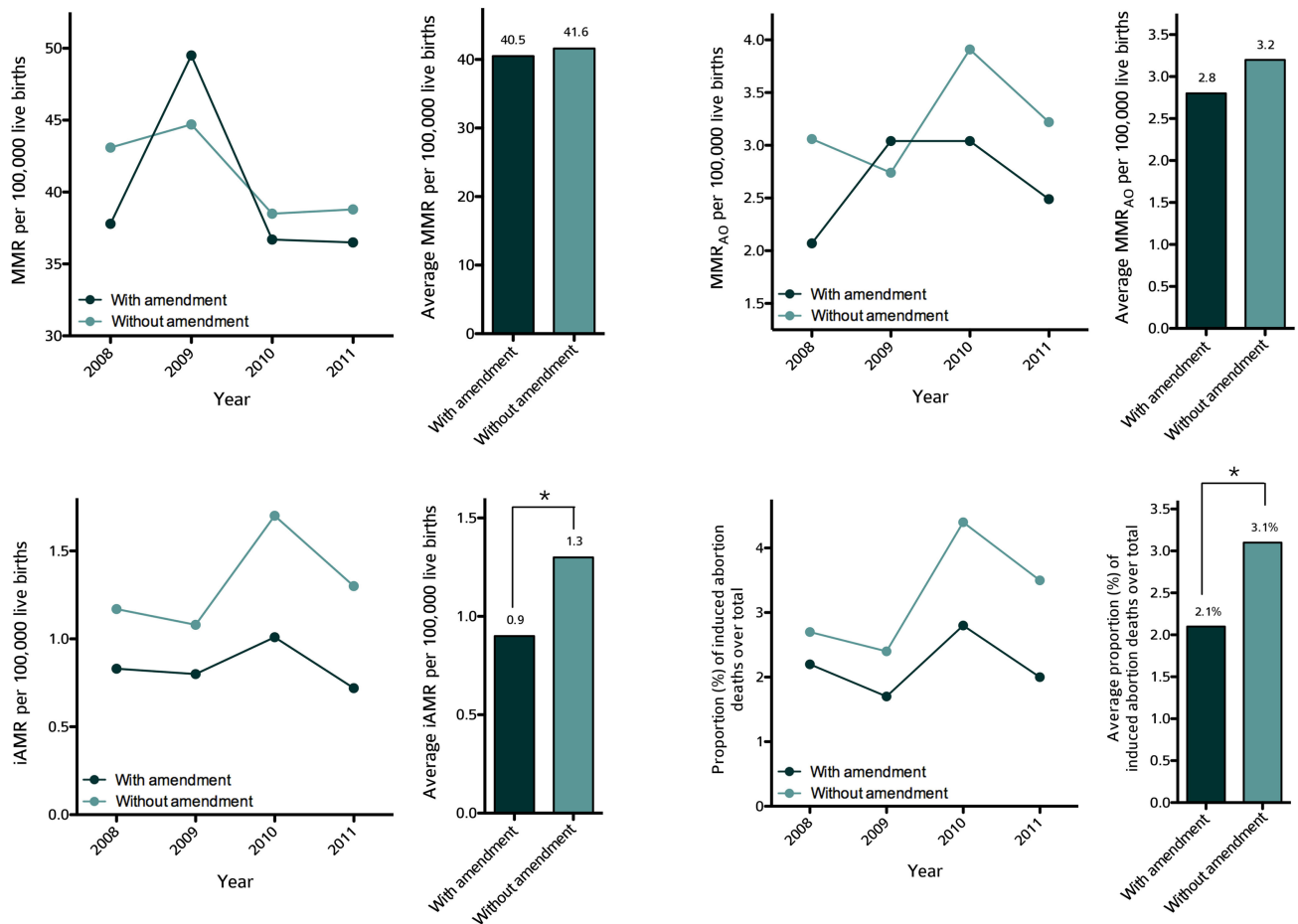

Figure 4 Mortality ratios and the proportion of abortion-related deaths by place of residence in states with or without a constitutional amendment to protect the unborn starting at conception. Line charts illustrate trends for MMR (top-left panel), $\mathrm{MMR}_{\mathrm{AO}}$ (top-right panel), iAMR (bottom-left panel) and the proportion of abortion-related deaths (bottom-right panel) by place of residence between 2008 and 2011 in Mexican states, grouped as with amendment (in dark green) or without amendment (in cyan) in terms of abortion legislation in their criminal code (see Materials and methods). Bar charts show average ratios and proportions of abortion-related deaths for each group (dark green and cyan bars, respectively). ${ }^{*} p<0.05$ using a Z-test. iAMR, induced abortion mortality ratio; MMR, maternal mortality ratio; $M_{M R R_{A O}, M M R}$ with abortive outcome. 
Indicators by place of occurrence
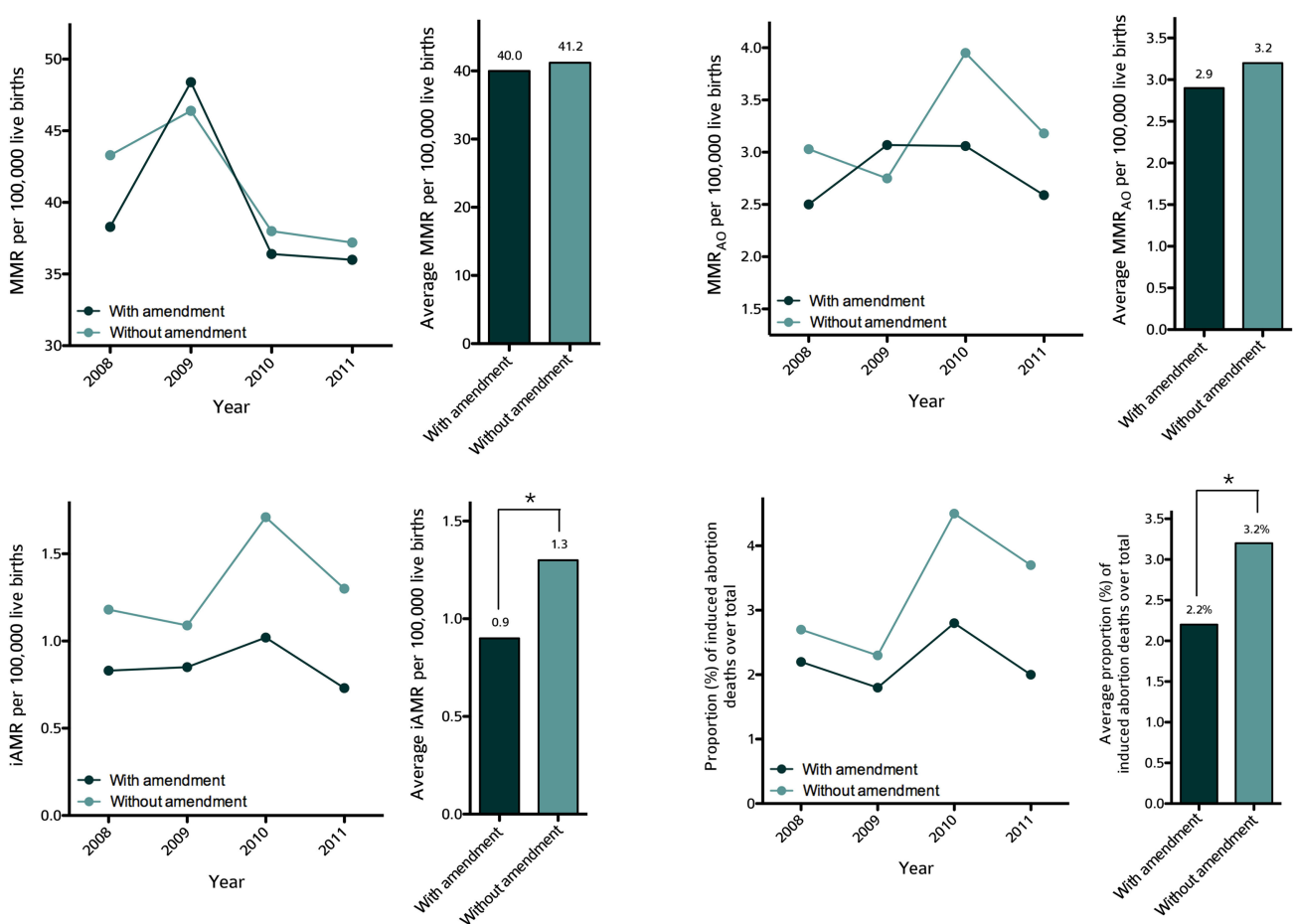

Figure 5 Mortality ratios and the proportion of abortion-related deaths by place of occurrence in states with or without a constitutional amendment to protect the unborn starting at conception. Line charts illustrate trends for MMR (top-left panel), $\mathrm{MMR}_{\mathrm{AO}}$ (top-right panel), iAMR (bottom-left panel) and the proportion of abortion-related deaths (bottom-right panel) by place of occurrence between 2008 and 2011 in Mexican states, grouped as with amendment (in dark green) or without amendment (in cyan) in terms of exhibiting or not a constitutional amendment to protect the unborn starting at conception (see online supplementary figure S1). Bar charts show average ratios and proportions of abortion-related deaths for each group (dark green and cyan bars, respectively). ${ }^{*} \mathrm{p}<0.05$ using Z-test. iAMR, induced abortion mortality ratio; MMR, maternal mortality ratio; MMR ${ }_{\mathrm{AO}}$, MMR with abortive outcome.

states, with an individual contribution of $17.8 \%$ and $27.9 \%$, respectively. For iAMR, the model selected three factors: clean water, low birth weight and skilled attendance at birth. These variables explained $70 \%\left(\mathrm{R}^{2}\right.$ for model $0.70 ; \mathrm{p}<0.001)$ of the difference among states with individual contributions of $39.2 \%, 26.6 \%$ and $7.4 \%$, respectively, of the differences observed in iAMR among states. Similarly, when female literacy was exchanged for sanitation, the refined model identified sanitation as inversely associated with MMR and iAMR. Finally, when TFR was incorporated instead of contraceptive use in multivariate models, an inverse independent association of TFR with MMR $(\beta=-14.329 ; p=0.002)$ and $\mathrm{MMR}_{\mathrm{AO}}(\beta=$ $-1.750 ; \mathrm{p}=0.008$ ), and a direct association with iAMR $(\beta=1.383 ; p=0.003)$ was found. A full description for other significant predictors in these alternative explanatory models is presented in the online supplementary material. No statistically significant effects were found for abortion legislation or constitutional amendment in any of the alternative regression models.

\section{DISCUSSION}

Diversity of abortion legislation in different regions, countries and territories may partially reflect different cultural values and attitudes towards motherhood, childhood, the unborn and abortion itself. ${ }^{22} \quad 41 \quad 43-47$ Theoretically, in Mexican states exhibiting less permissive legislation, maternal mortality should have been higher because the practice of unsafe abortion should be more frequent. ${ }^{19-22}$ Paradoxically, over a 10-year period, those states almost univocally exhibited lower figures for MMR, $\mathrm{MMR}_{\mathrm{AO}}$ and iAMR. Nevertheless, after an exhaustive analysis adjusting for multiple confounders, the initial estimated effects for all mortality outcomes were explained by differences in other independent factors known to influence maternal health rather than by abortion legislation itself. In fact, most of the independent variables considered in the present study were more favourably distributed in the group of states with less permissive legislation in a weighted comparative analysis (table 9). Consequently, making a direct or independent causal link between a less permissive abortion law and a lower incidence of maternal deaths-or conversely by considering a more permissive abortion law-would be a premature or even erroneous conclusion. Rather, from an epidemiological perspective, the Mexican natural experiment provides evidence to support three complementary assumptions at the population level: first, abortion legislation per se did not appear to have an independent effect 


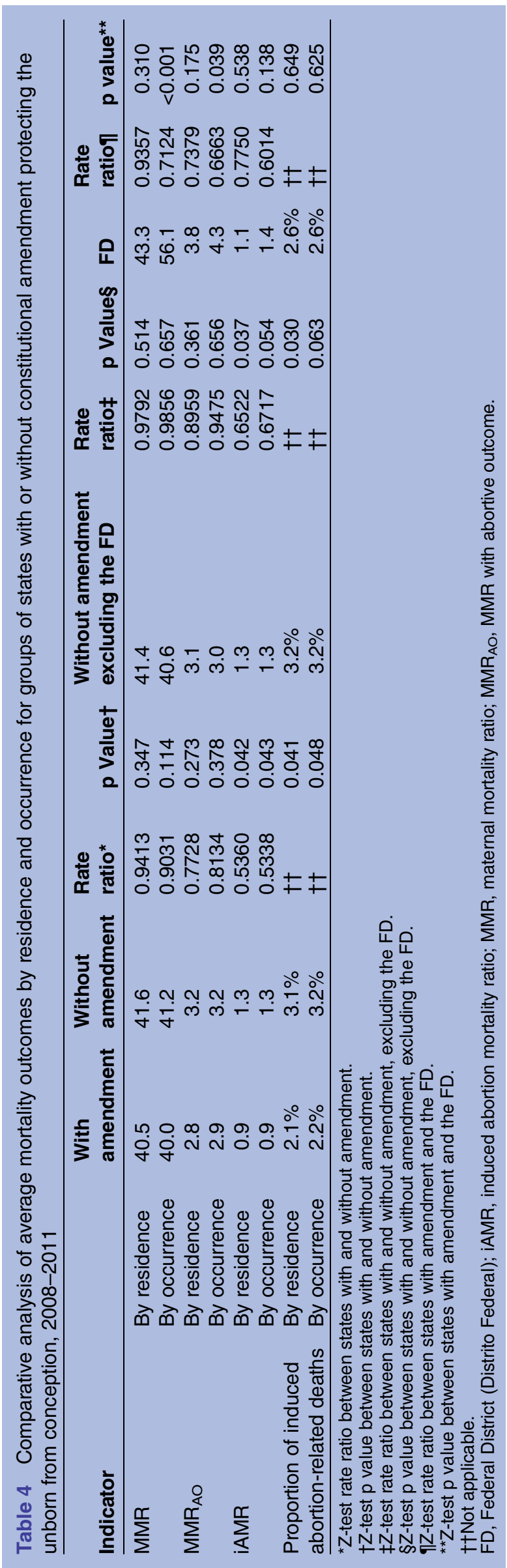

on overall maternal mortality rates; second, a less permissive abortion law, in terms of not considering exemptions from criminal prosecution of abortion in cases of genetic or congenital fetal anomalies, was not associated with increased maternal and abortion-related deaths; and third, differences in maternal mortality incidence in the context of different abortion legislation (more or less permissive), appear to be mainly explained by the distribution of other major independent factors most likely facilitating an epidemiological transition towards low maternal mortality rates independently from abortion legislation itself.

On the other hand, whether state constitutional amendments protecting the unborn translate into higher or lower maternal mortality rates has not yet been explored. Theoretically, these states might be culturally more reluctant to accept changes in abortion legislation, ${ }^{22} 434546$ and therefore maternal deaths might be higher, particularly if practice of unsafe abortions is frequent. ${ }^{21}{ }^{47}$ At least in the short term, this natural experiment found no evidence of any detrimental impact on maternal mortality outcomes related to constitutional amendments protecting the unborn. Some differences were noted between groups of states with and without amendments between 2008 and 2011, that is, lower average iAMR and lower average proportion of abortion-related deaths in the group of states with amendments compared with the group without amendments. Nevertheless, in multivariate models, these differences appeared to be explained by other independent factors distributed more favourably in the group of states with less permissive legislation but unrelated to constitutional amendment.

Interestingly, between 2008 and 2011, the Federal District displayed higher $\mathrm{MMR}$ and $\mathrm{MMR}_{\mathrm{AO}}$ than did the group of states with the constitutional amendment, when the outcome was measured by place of occurrence, but not by place of residence. Indeed, when mortality ratios by occurrence or residence are compared state by state, the Federal District showed the highest difference in maternal mortality outcomes (eg, 61.9 vs 48.7 for MMR per 100000 live births, respectively). From an epidemiological perspective, such disparities often reflect a pattern of temporary mobility among the population. ${ }^{48}$ Similarly, the difference in iAMR and the proportion of abortion-related deaths by place of occurrence between states with and without amendment was abolished when the Federal District was removed from the latter group. Thus, interstate mobility into the Federal District appears to be associated with an increased risk of maternal mortality for pregnant women arriving from other states. Determinants of this phenomenon are largely unknown and warrant further research.

Multivariate regression in primary and alternative models (refined or unrefined) revealed that a combination of factors related to maternal healthcare, reproductive behaviour, access to clean water, sanitation, 
Indicators by place of residence
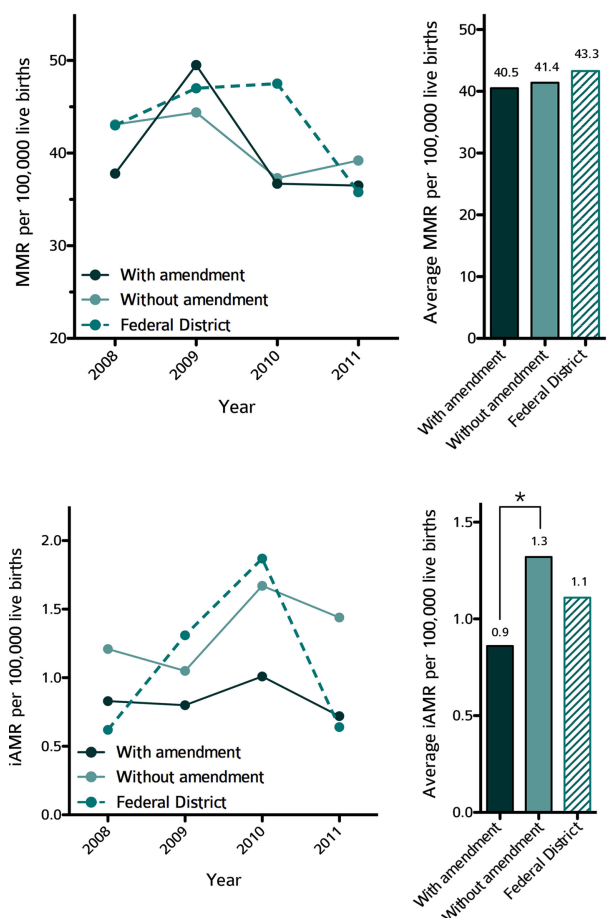
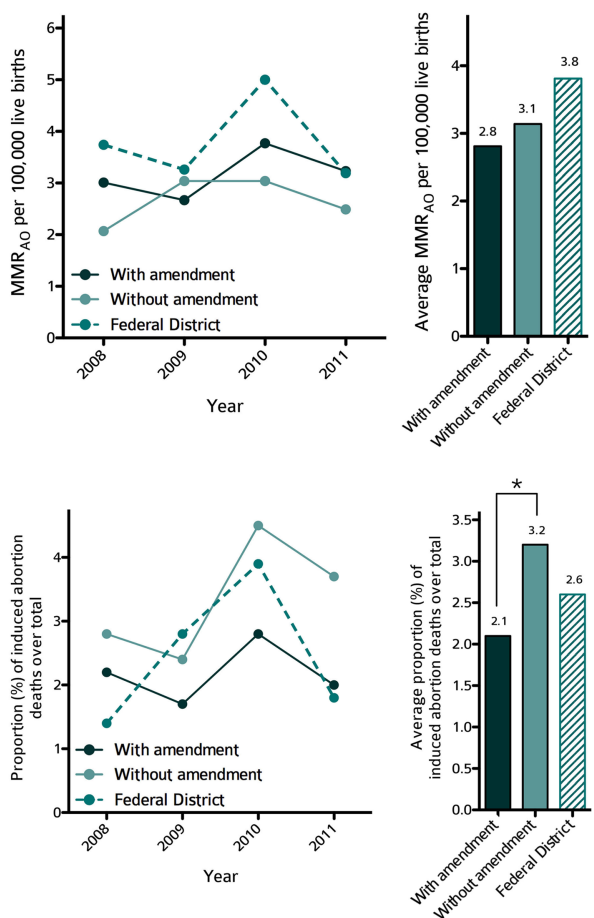

Figure 6 Mortality ratios and proportions of abortion-related deaths by place of residence in states with or without constitutional amendment to protect the unborn starting at conception: focus on the Federal District. Line charts illustrate trends for MMR (topleft panel), $M_{M} R_{A O}$ (top-right panel), iAMR (bottom-left panel) and the proportion of abortion-related deaths (bottom-right panel) by place of occurrence between 2008 and 2011 in Mexican states, grouped as with amendment (in dark green), without amendment (in cyan), and the Federal District (hatched) in terms of exhibiting or not a constitutional amendment (the Federal District of Mexico was not included in this group to be illustrated separately) to protect the unborn starting at conception (see online supplementary figure S1). Bar charts show average ratios and proportions of abortion-related deaths for each group (dark green, cyan and hatched bars, respectively). ${ }^{*} \mathrm{p}<0.05$ using Z-test. iAMR, induced abortion mortality ratio; MMR, maternal mortality ratio; $M_{M} R_{A O}, M M R$ with abortive outcome.

female literacy and intimate-partner violence against women explained $51-88 \%$ of the variance among states in overall maternal mortality rates. Proportional contributions of each variable explaining the variance of maternal mortality outcomes analysed among Mexican states are summarised in figure 8. These percentages also represent the potential impact of addressing each factor individually to decrease mortality ratios in Mexico. Box 1 summarises public health interventions based on the results of this study to improve maternal health in this country.

Regarding maternal healthcare, three factors resulted that were independently associated with maternal mortality outcomes. First, consistent with the general consensus, ${ }^{3} 6$ 8-10 49-51 skilled attendance at birth showed an inverse relationship with mortality ratios: for each $1 \%$ increase in skilled attendance at birth, decreases of 0.42 in MMR (see online supplementary table S16), 0.06 in $\mathrm{MMR}_{\mathrm{AO}}$ and 0.05 in iAMR per 100000 live births were estimated. This factor-ranging from $75 \%$ to $99 \%$ among states (table 5)-most likely reflects important disparities in access to antenatal care and institutional deliveries. ${ }^{45} 5051$ Second, the all-abortion hospitalisation ratio showed an inverse relationship with MMR in refined explanatory models. For each incremental unit of this variable, a decrease of 0.8 maternal deaths per 100000 live births was estimated among states. This inverse relationship has been previously identified as an indicator of improved access to emergency obstetric units and specialised obstetric and postabortion care. $^{27} \quad 30 \quad 42$ 52-54 In contrast, a direct relationship between the all-abortion hospitalisation ratio and MMR may indicate high rates of in-hospital deaths secondary to obstetric complications or, alternatively, that an important number of unsafe abortions are being conducted. ${ }^{27} 30$ 54-57 This second interpretation seems not to be the case in Mexico. Finally, a low birth weight rate showed strong direct associations with all mortality ratios in multivariate models: for each $1 \%$ increase in low birth weight, increases of 1.6 in MMR, 0.3 in $\mathrm{MMR}_{\mathrm{AO}}$ and 0.1 in iAMR per 100000 live births were estimated, explaining from $15.1 \%$ to $40.2 \%$ of the variance among states. An association between low birth weight and mortality ratios may be explained by the fact that low birth weight and preterm birth are proxies for adverse pregnancy outcomes related to a series of antecedent 
Indicators by place of occurrence
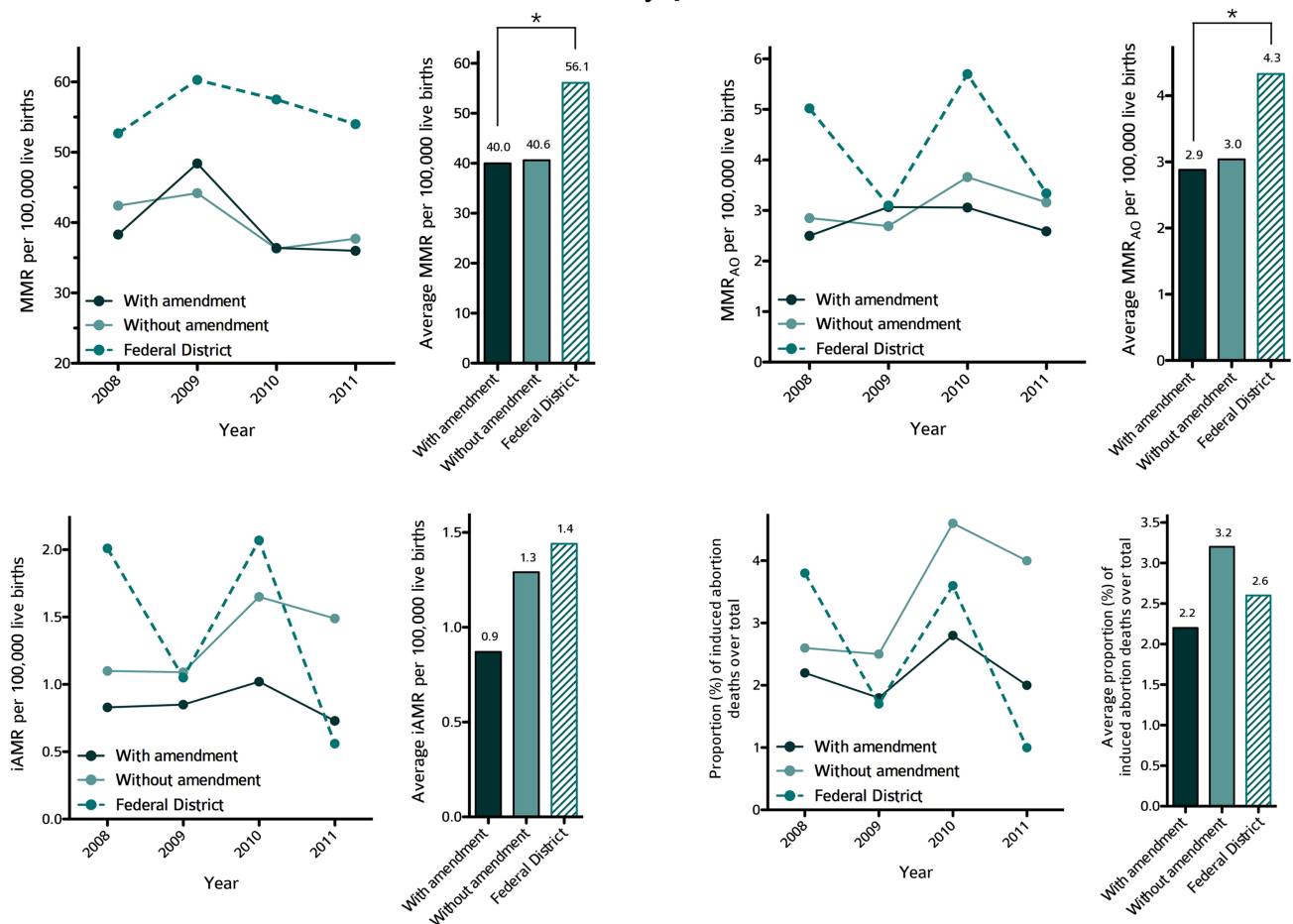

Figure 7 Mortality ratios and the proportion of abortion-related deaths by place of occurrence in states with or without a constitutional amendment to protect the unborn starting at conception: focus on the Federal District. Line charts illustrate trends for MMR (top-left panel), $\mathrm{MMR}_{\mathrm{AO}}$ (top-right panel), iAMR (bottom-left panel) and the proportion of abortion-related deaths (bottom-right panel) by place of residence between 2008 and 2011 in Mexican states, grouped as with amendment (in dark green), without amendment (in cyan) and the Federal District (hatched) in terms of exhibiting or not an constitutional amendment (the Federal District of Mexico was not included in this group to be illustrated separately) to protect the unborn starting at conception (see online supplementary figure S1). Bar charts show average ratios and proportions of abortion-related deaths for each group (dark green, cyan and hatched bars, respectively). ${ }^{\star} p<0.05$ using Z-test. iAMR, induced abortion mortality ratio; MMR, maternal mortality ratio; $\mathrm{MMR}_{\mathrm{AO}}$, MMR with abortive outcome.

individual risk factors and medical conditions, such as advanced maternal age, poor nutrition, infections, preeclampsia, placental abnormalities, cervical incompetence, cardiovascular conditions, pre-existing chronic diseases, drug addiction, adverse social situation, alcohol abuse, insufficient prenatal care and a gynaecological history of previous termination of pregnancy. ${ }^{58-62}$ Taking into consideration the wide disparity in low birth weight rates among states (from $5.4 \%$ to $14.0 \%$ ), individuallevel risk factors most likely make a major contribution to current maternal mortality rates in Mexico. This suggests the need for an expansion of emergency obstetric units, specialised diagnostic centres and prenatal care for high-risk pregnancies, and the incorporation of other medical specialties, which in turn may favourably impact maternal health. ${ }^{4} 7063-65$

Reproductive behaviour is another factor most likely influencing maternal health. In this study, two variables were considered as proxies of the reproductive behaviour: contraceptive use and the average TFR between 2002 and 2011 for each state (table 5). ${ }^{10} 3066-69$ This study provided little evidence that contraceptive use exerts an independent primary influence on maternal mortality differences among Mexican states over the past decade.
Nevertheless, alternative multivariate models considering TFR instead of contraceptive use revealed two opposite effects of TFR on mortality ratios: while displaying an inverse relationship with $\mathrm{MMR}$ and $\mathrm{MMR}_{\mathrm{AO}}$, TFR showed a direct association with iAMR, explaining $17.2 \%$ of the difference in abortion-related mortality among states. The direct association of TFR with iAMR may be related to an increased number of unplanned pregnancies terminated with abortion. In contrast, the inverse association between TFR and MMR or $M_{M M R}$ is more difficult to interpret. Simple direct correlations between TFR and MMR across multiple countries support the common notion that decreasing fertility reduces maternal mortality by reducing a woman's exposure to pregnancy during her reproductive lifetime. ${ }^{10} 666770$ However, results from recent studies show that the relationship between TFR and maternal mortality is much more complex and may vary from one country to another. ${ }^{30657172}$ A plausible mechanism to explain an inverse correlation between TFR and maternal mortality has been referred to as the 'fertility paradox' emerging in advanced stages of demographic transition, when TFR falls under $2.5 .{ }^{30}$ While early stages of fertility reduction would be associated with a 
Table 5 Independent variables in each Mexican state: frequencies and analyses of normal distribution

\begin{tabular}{|c|c|c|c|c|c|c|c|c|c|c|c|}
\hline State & $\begin{array}{l}\text { Abortion } \\
\text { legislation }\end{array}$ & $\begin{array}{l}\text { Constitutional } \\
\text { amendment }\end{array}$ & $\begin{array}{l}\text { Clean } \\
\text { water }\end{array}$ & Sanitation & TFR & $\begin{array}{l}\text { Contraceptive } \\
\text { use }\end{array}$ & $\begin{array}{l}\text { Skilled } \\
\text { attendance } \\
\text { at birth }\end{array}$ & $\begin{array}{l}\text { Low } \\
\text { birth } \\
\text { weight }\end{array}$ & $\begin{array}{l}\text { Female } \\
\text { literacy }\end{array}$ & $\begin{array}{l}\text { All-abortion } \\
\text { hospitalisation } \\
\text { ratio }\end{array}$ & $\begin{array}{l}\text { Intimate-partner } \\
\text { violence }\end{array}$ \\
\hline Aguascalientes & 1 & 0 & 98.0 & 97.8 & 2.6 & 71.7 & 97.5 & 6.6 & 95.9 & 10.8 & 12.0 \\
\hline Baja California & 1 & 1 & 95.3 & 93.7 & 2.1 & 78.8 & 75.7 & 6.9 & 96.0 & 9.2 & 11.7 \\
\hline $\begin{array}{l}\text { Baja California } \\
\text { Sur }\end{array}$ & 0 & 0 & 88.1 & 94.2 & 2.0 & 75.9 & 99.5 & 6.0 & 95.8 & 10.6 & 16.3 \\
\hline Campeche & 1 & 0 & 85.0 & 85.7 & 2.2 & 73.9 & 98.2 & 7.2 & 89.7 & 7.8 & 10.7 \\
\hline Coahuila & 0 & 0 & 96.8 & 95.6 & 2.3 & 75.2 & 89.6 & 8.0 & 96.5 & 8.0 & 14.3 \\
\hline Colima & 0 & 1 & 97.3 & 98.7 & 2.3 & 78.3 & 96.4 & 5.4 & 94.2 & 17.4 & 11.0 \\
\hline Chiapas & 0 & 1 & 73.8 & 80.4 & 2.8 & 54.9 & 90.2 & 8.6 & 77.5 & 5.1 & 7.0 \\
\hline Chihuahua & 1 & 1 & 94.9 & 93.2 & 2.4 & 78.9 & 82.2 & 7.6 & 95.3 & 6.2 & 12.1 \\
\hline Distrito Federal & 0 & 0 & 97.5 & 99.2 & 1.8 & 79.6 & 94.3 & 14.0 & 96.3 & 14.2 & 20.9 \\
\hline Durango & 1 & 1 & 92.9 & 88.3 & 2.4 & 73.2 & 93.3 & 8.0 & 95.5 & 8.2 & 10.2 \\
\hline Guanajuato & 1 & 1 & 91.9 & 89.3 & 2.4 & 68.3 & 90.1 & 8.9 & 90.1 & 7.0 & 6.4 \\
\hline Guerrero & 0 & 0 & 62.0 & 71.7 & 2.8 & 61.4 & 80.8 & 9.3 & 79.8 & 3.2 & 8.3 \\
\hline Hidalgo & 0 & 0 & 87.2 & 83.4 & 2.4 & 70.9 & 89.7 & 8.5 & 87.2 & 6.2 & 8.6 \\
\hline Jalisco & 1 & 1 & 94.6 & 96.9 & 2.4 & 71.4 & 93.5 & 9.0 & 94.8 & 7.4 & 10.0 \\
\hline México & 0 & 0 & 92.2 & 92.0 & 2.2 & 76.5 & 84.7 & 10.9 & 93.6 & 4.4 & 11.9 \\
\hline Michoacán & 1 & 0 & 88.1 & 85.4 & 2.4 & 63.2 & 92.1 & 8.6 & 88.4 & 6.1 & 9.1 \\
\hline Morelos & 0 & 1 & 87.6 & 92.4 & 2.2 & 75.4 & 91.7 & 10.5 & 91.8 & 8.8 & 9.7 \\
\hline Nayarit & 1 & 1 & 88.3 & 93.5 & 2.3 & 78.7 & 81.8 & 6.8 & 92.9 & 7.4 & 14.8 \\
\hline Nuevo León & 1 & 0 & 96.9 & 97.2 & 2.1 & 79.2 & 96.6 & 8.6 & 95.8 & 6.5 & 13.1 \\
\hline Oaxaca & 0 & 1 & 69.8 & 69.6 & 2.6 & 63.4 & 95.0 & 7.8 & 79.4 & 3.7 & 6.3 \\
\hline Puebla & 0 & 1 & 83.8 & 84.9 & 2.6 & 69.8 & 90.8 & 9.6 & 86.8 & 4.0 & 8.6 \\
\hline Querétaro & 1 & 1 & 91.9 & 91.0 & 2.3 & 70.3 & 97.6 & 9.2 & 91.7 & 9.1 & 11.6 \\
\hline Quintana Roo & 0 & 1 & 91.7 & 94.0 & 2.1 & 73.4 & 91.5 & 8.3 & 92.4 & 9.7 & 10.7 \\
\hline San Luis Potosí & 1 & 1 & 83.1 & 80.5 & 2.5 & 67.4 & 91.7 & 8.1 & 90.5 & 6.6 & 10.5 \\
\hline Sinaloa & 1 & 0 & 90.3 & 90.9 & 2.3 & 79.8 & 93.4 & 6.1 & 94.7 & 8.1 & 15.0 \\
\hline Sonora & 1 & 1 & 94.4 & 90.0 & 2.4 & 79.9 & 94.6 & 6.2 & 96.3 & 8.7 & 15.4 \\
\hline Tabasco & 1 & 0 & 73.8 & 91.7 & 2.3 & 66.3 & 82.4 & 8.4 & 90.9 & 7.2 & 9.6 \\
\hline Tamaulipas & 1 & 1 & 95.1 & 88.1 & 2.3 & 73.2 & 99.0 & 7.4 & 94.2 & 10.0 & 14.9 \\
\hline Tlaxcala & 1 & 0 & 95.6 & 92.8 & 2.4 & 65.2 & 98.2 & 10.1 & 92.8 & 7.6 & 9.3 \\
\hline Veracruz & 0 & 0 & 76.3 & 80.2 & 2.2 & 73.9 & 97.8 & 7.1 & 86.1 & 4.8 & 10.9 \\
\hline Yucatán & 0 & 1 & 94.4 & 80.1 & 2.3 & 74.9 & 97.5 & 10.7 & 88.6 & 7.2 & 11.5 \\
\hline Zacatecas & 1 & 0 & 91.7 & 89.0 & 2.5 & 70.2 & 89.1 & 8.6 & 93.6 & 8.3 & 8.2 \\
\hline p Value ${ }^{*}$ & $\dagger$ & $\dagger$ & 0.189 & 0.624 & 0.311 & 0.730 & 0.534 & 0.666 & 0.399 & 0.394 & 0.505 \\
\hline
\end{tabular}

0.666

Abortion legislation: states classified as less permissive (1) or more permissive (0), according to the presence of an exemption from criminal prosecution of abortion in cases of genetic or

congenital malformation. Constitutional amendment: states classified as exhibiting (1) or not (0) an amendment to their political constitution protecting the unborn from conception during 2011. Clean water: percentage of in-use private dwellings with clean water availability during 2010. Sanitation: percentage of in-use private dwellings with availability of sewer drainage during 2010. TFR: average total fertility rate between 2002 and 2011. Contraceptive use: percentage of married or in-union women of 15 and above using contraceptive methods during 2009 . Skilled attendance at birth: percentage of observed live births delivered by a physician, nurse or midwife during 2010. Low birth weight: percentage of observed live births with low birth weight in each state during 2010. Female literacy: percentage of the female population of ages 15 and above who can understand, read and write a short, simple statement on their everyday life during 2010. All-abortion hospitalisation ratio: ratio of all-abortion related hospitalisations over observed live births between 2000 and 2008 per 100 live births. Intimate-partner violence: percentage of

married or in-union women of ages 15 and above who have suffered severe intimate partner violence over the past 12 months during 2010.

*Kolmogorov-Smirnov test for normal distribution.

†Not applicable. 
Table 6 Univariate associations between 10 independent variables and maternal mortality outcomes for 32 Mexican states, 2002-2011

\begin{tabular}{|c|c|c|c|c|c|c|c|c|c|c|c|c|c|c|c|c|c|c|}
\hline \multirow[b]{3}{*}{ Variable } & \multicolumn{6}{|l|}{ MMR } & \multicolumn{6}{|c|}{$\mathrm{MMR}_{\mathrm{AO}}$} & \multicolumn{6}{|l|}{ iAMR } \\
\hline & \multirow[b]{2}{*}{$\boldsymbol{\beta}$} & \multirow[b]{2}{*}{ SE } & \multicolumn{2}{|l|}{$95 \% \mathrm{Cl}$} & \multirow[b]{2}{*}{$\mathbf{R}^{2}$} & \multirow[b]{2}{*}{ p Value } & \multirow[b]{2}{*}{$\boldsymbol{\beta}$} & \multirow[b]{2}{*}{ SE } & \multicolumn{2}{|l|}{$95 \% \mathrm{Cl}$} & \multirow[b]{2}{*}{$\mathbf{R}^{2}$} & \multirow[b]{2}{*}{ p Value } & \multirow[b]{2}{*}{$\boldsymbol{\beta}$} & \multirow[b]{2}{*}{ SE } & \multicolumn{2}{|l|}{$95 \% \mathrm{Cl}$} & \multirow[b]{2}{*}{$\mathbf{R}^{2}$} & \multirow[b]{2}{*}{ p Value } \\
\hline & & & Lower & Upper & & & & & Lower & Upper & & & & & Lower & Upper & & \\
\hline Female literacy (\%) & -1.16 & 0.26 & -1.700 & -0.627 & 0.38 & $<0.001$ & -0.08 & 0.03 & -0.155 & -0.007 & 0.11 & 0.033 & -0.07 & 0.02 & -0.117 & -0.021 & 0.20 & 0.007 \\
\hline Low birth weight (\%) & 2.05 & 0.92 & 0.173 & 3.937 & 0.11 & 0.033 & 0.33 & 0.09 & 0.134 & 0.534 & 0.26 & 0.002 & 0.17 & 0.07 & 0.025 & 0.319 & 0.13 & 0.023 \\
\hline Skilled attendance at birth (\%) & -0.52 & 0.27 & -1.067 & 0.023 & 0.08 & 0.060 & -0.08 & 0.03 & -0.140 & -0.020 & 0.17 & 0.010 & -0.03 & 0.02 & -0.073 & 0.015 & 0.02 & 0.192 \\
\hline Intimate-partner violence (\%) & -0.86 & 0.52 & -1.931 & 0.205 & 0.05 & 0.109 & -0.06 & 0.06 & -0.189 & 0.066 & 0.00 & 0.332 & -0.05 & 0.04 & -0.138 & 0.034 & 0.02 & 0.230 \\
\hline $\begin{array}{l}\text { All-abortion hospitalisation ratio } \\
\text { (per } 100 \text { live births) }\end{array}$ & -1.71 & 0.51 & -2.750 & -0.678 & 0.25 & 0.002 & -0.11 & 0.06 & -0.247 & 0.022 & 0.05 & 0.099 & -0.10 & 0.04 & -0.187 & -0.009 & 0.11 & 0.033 \\
\hline Constitutional amendment (yes) & 1.93 & 3.36 & -4.946 & 8.809 & 0.01 & 0.571 & 0.22 & 0.39 & -0.575 & 1.019 & -0.02 & 0.574 & -0.20 & 0.26 & -0.742 & 0.340 & -0.01 & 0.454 \\
\hline $\begin{array}{l}\text { Abortion legislation (less } \\
\text { permissive) }\end{array}$ & -7.31 & 3.13 & -13.710 & -0.911 & 0.12 & 0.027 & -0.47 & 0.38 & -1.263 & 0.310 & 0.01 & 0.226 & -0.31 & 0.26 & -0.843 & 0.232 & 0.01 & 0.255 \\
\hline Contraceptive use (\%) & -0.64 & 0.25 & -1.165 & -0.130 & 0.15 & 0.016 & -0.04 & 0.03 & -0.106 & 0.023 & 0.02 & 0.195 & -0.05 & 0.02 & -0.093 & -0.012 & 0.16 & 0.013 \\
\hline TFR & 9.51 & 6.56 & -3.899 & 22.927 & 0.03 & 0.158 & 0.46 & 0.78 & -1.134 & 2.063 & -0.02 & 0.557 & 1.21 & 0.48 & 0.221 & 2.216 & 0.14 & 0.018 \\
\hline Clean water (\%) & -0.66 & 0.15 & -0.970 & -0.355 & 0.37 & $<0.001$ & -0.03 & 0.02 & -0.076 & 0.012 & 0.03 & 0.152 & -0.03 & 0.01 & -0.065 & -0.009 & 0.16 & 0.012 \\
\hline Sanitation (\%) & -0.79 & 0.18 & -1.174 & -0.425 & 0.36 & $<0.001$ & -0.03 & 0.02 & -0.090 & 0.017 & 0.02 & 0.177 & -0.04 & 0.01 & -0.075 & -0.005 & 0.12 & 0.026 \\
\hline
\end{tabular}

iAMR, induced abortion mortality ratio; MMR, maternal mortality ratio; $M_{M R}$, MMR with abortive outcome; TFR, average total fertility rate between $2002-2011$.

Table 7 Explanatory models for trends on MMR, MMR ${ }_{A O}$ and iAMR in 32 Mexican states after refinement, 2002-2011

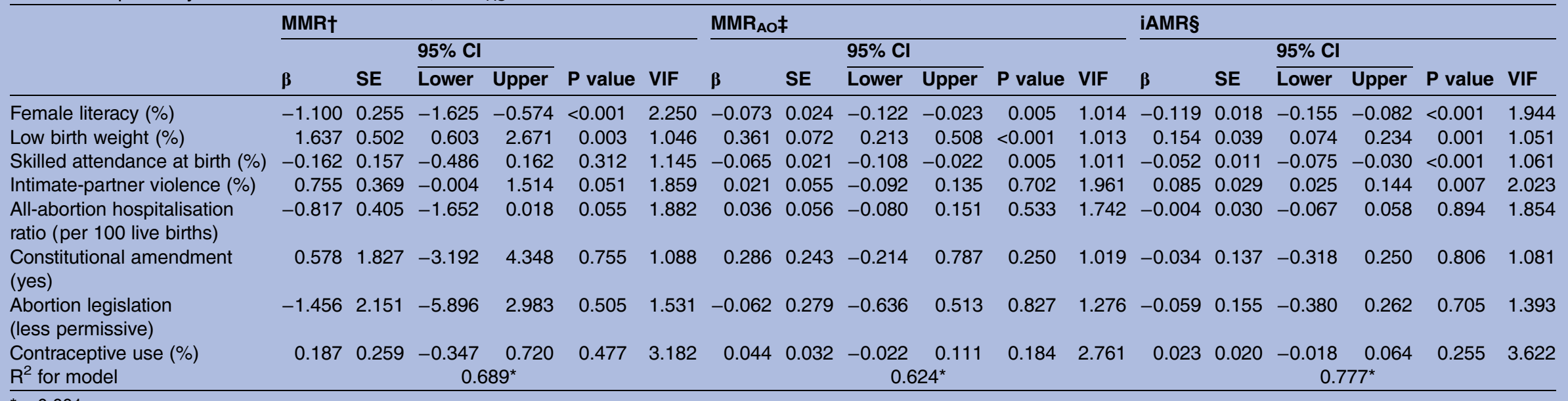

${ }^{*} \mathrm{p}<0.001$.

†Multivariate model identified and excluded two states (Chihuahua and Nueva León) as outliers after one step of refinement. Four predictors were identified after five steps of backward elimination (female literacy, low birth weight, all-abortion hospitalisation ratio and intimate-partner violence), accounting for $69 \%$ ( $\left.R^{2}\right)$ of the differences in MMR between states.

$\neq$ Multivariate model identified and excluded two states (Aguascalientes and Nayarit) as outliers after two steps of refinement. Three predictors were identified after six steps of backward elimination (female literacy, low birth weight and skilled attendance at birth), accounting for $62 \%\left(R^{2}\right)$ of the differences in MMR $R_{A O}$ between states.

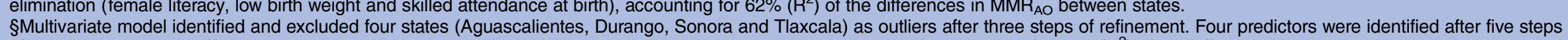

of backward elimination (female literacy, low birth weight, skilled attendance at birth and intimate-partner violence), accounting for $78 \%$ ( $\left.R^{2}\right)$ of the differences in iAMR between states.

iAMR, induced abortion mortality ratio; MMR, maternal mortality ratio; MMR $\mathrm{AO}_{\mathrm{O}}$, MMR with abortive outcome; VIF, variance inflation factor. 
Table 8 Alternative explanatory regression models for MMR, MMR $A$ and iAMR after refinement considering independent variables excluded from the explanatory models because of collinearity

\begin{tabular}{|c|c|c|c|c|c|c|c|c|c|c|c|c|c|c|c|c|c|c|}
\hline \multirow[b]{3}{*}{ Variable } & \multicolumn{6}{|l|}{ MMR } & \multicolumn{6}{|l|}{$\mathrm{MMR}_{\mathrm{AO}}$} & \multicolumn{6}{|l|}{ iAMR } \\
\hline & \multirow[b]{2}{*}{$\boldsymbol{\beta}$} & \multirow[b]{2}{*}{ SE } & \multicolumn{2}{|l|}{$95 \% \mathrm{Cl}$} & \multirow[b]{2}{*}{$p$ value } & \multirow[b]{2}{*}{ VIF } & \multirow[b]{2}{*}{$\boldsymbol{\beta}$} & \multirow[b]{2}{*}{ SE } & \multicolumn{2}{|l|}{$95 \% \mathrm{CI}$} & \multirow[b]{2}{*}{$p$ value } & \multirow[b]{2}{*}{ VIF } & \multirow[b]{2}{*}{$\boldsymbol{\beta}$} & \multirow[b]{2}{*}{ SE } & \multicolumn{2}{|l|}{$95 \% \mathrm{Cl}$} & \multirow[b]{2}{*}{$\mathrm{p}$ value } & \multirow[b]{2}{*}{ VIF } \\
\hline & & & Lower & Upper & & & & & Lower & Upper & & & & & Lower & Upper & & \\
\hline Clean water (\%) & -0.730 & 0.085 & -0.908 & -0.553 & $<0.001$ & 1.928 & -0.021 & 0.017 & -0.056 & 0.014 & 0.225 & 1.066 & -0.048 & 0.008 & -0.065 & -0.030 & $<0.001$ & 1.041 \\
\hline Low birth weight (\%) & 1.938 & 0.318 & 1.279 & 2.596 & $<0.001$ & 1.086 & 0.321 & 0.087 & 0.144 & 0.498 & 0.001 & 1.002 & 0.210 & 0.043 & 0.121 & 0.299 & $<0.001$ & 1.006 \\
\hline Skilled attendance at birth (\%) & -0.027 & 0.106 & -0.250 & 0.197 & 0.806 & 1.238 & -0.076 & 0.025 & -0.126 & -0.026 & 0.004 & 1.002 & -0.032 & 0.012 & -0.057 & -0.007 & 0.014 & 1.039 \\
\hline Intimate-partner violence (\%) & 0.554 & 0.210 & 0.118 & 0.990 & 0.015 & 1.570 & 0.010 & 0.078 & -0.150 & 0.170 & 0.897 & 2.446 & 0.033 & 0.029 & -0.028 & 0.093 & 0.276 & 1.615 \\
\hline $\begin{array}{l}\text { All-abortion hospitalisation ratio (per } \\
100 \text { live births) }\end{array}$ & -0.566 & 0.271 & -1.129 & -0.003 & 0.049 & 2.288 & -0.010 & 0.080 & -0.176 & 0.156 & 0.901 & 2.107 & -0.020 & 0.036 & -0.095 & 0.055 & 0.580 & 2.056 \\
\hline Constitutional amendment (yes) & -0.312 & 1.172 & -2.765 & 2.141 & 0.793 & 1.136 & 0.316 & 0.295 & -0.289 & 0.921 & 0.294 & 1.031 & 0.112 & 0.148 & -0.194 & 0.418 & 0.457 & 1.032 \\
\hline Abortion legislation (less permissive) & 1.745 & 1.361 & -1.095 & 4.585 & 0.215 & 1.625 & -0.085 & 0.335 & -0.773 & 0.604 & 0.803 & 1.269 & -0.158 & 0.163 & -0.496 & 0.180 & 0.344 & 1.266 \\
\hline Contraceptive use (\%) & 0.167 & 0.150 & -0.144 & 0.479 & 0.276 & 2.756 & -0.007 & 0.037 & -0.083 & 0.068 & 0.843 & 2.160 & 0.009 & 0.024 & -0.042 & 0.059 & 0.723 & 3.798 \\
\hline$R^{2}$ for model & $0.886^{*}$ & & & & & & $0.420^{*}$ & & & & & & $0.700^{*}$ & & & & & \\
\hline Sanitation (\%) & -0.758 & 0.127 & -1.019 & -0.497 & $<0.001$ & 1.001 & -0.032 & 0.020 & -0.072 & 0.009 & 0.121 & 1.002 & -0.052 & 0.011 & -0.075 & -0.029 & $<0.001$ & 1.000 \\
\hline Low birth weight (\%) & 2.166 & 0.528 & 1.082 & 3.249 & $<0.001$ & 1.001 & 0.321 & 0.087 & 0.144 & 0.498 & 0.001 & 1.002 & 0.169 & 0.048 & 0.070 & 0.268 & 0.002 & 1.003 \\
\hline Skilled attendance at birth (\%) & -0.248 & 0.154 & -0.565 & 0.069 & 0.120 & 1.008 & -0.076 & 0.025 & -0.126 & -0.026 & 0.004 & 1.002 & -0.044 & 0.014 & -0.072 & -0.016 & 0.004 & 1.003 \\
\hline Intimate-partner violence (\%) & 0.238 & 0.337 & -0.457 & 0.933 & 0.487 & 1.490 & 0.023 & 0.078 & -0.137 & 0.183 & 0.772 & 2.494 & 0.055 & 0.031 & -0.010 & 0.119 & 0.092 & 1.592 \\
\hline $\begin{array}{l}\text { All-abortion hospitalisation ratio (per } \\
100 \text { live births) }\end{array}$ & -0.410 & 0.518 & -1.485 & 0.665 & 0.438 & 2.903 & 0.019 & 0.090 & -0.167 & 0.205 & 0.835 & 2.693 & -0.005 & 0.046 & -0.101 & 0.091 & 0.920 & 2.605 \\
\hline Constitutional amendment (Yes) & 0.660 & 1.958 & -3.412 & 4.732 & 0.739 & 1.175 & 0.232 & 0.292 & -0.368 & 0.831 & 0.434 & 1.026 & 0.090 & 0.166 & -0.254 & 0.434 & 0.593 & 1.083 \\
\hline Abortion legislation (less permissive) & -3.148 & 1.875 & -7.010 & 0.714 & 0.106 & 1.164 & -0.104 & 0.322 & -0.767 & 0.558 & 0.749 & 1.194 & -0.192 & 0.172 & -0.546 & 0.163 & 0.276 & 1.206 \\
\hline $\begin{array}{l}\text { Contraceptive use (\%) } \\
\mathrm{R}^{2} \text { for model }\end{array}$ & $\begin{array}{r}-0.241 \\
0.640^{*}\end{array}$ & 0.239 & -0.737 & 0.254 & 0.324 & 2.671 & $\begin{array}{r}-0.005 \\
0.420^{*}\end{array}$ & 0.033 & -0.072 & 0.062 & 0.873 & 1.743 & $\begin{aligned}-0.011 \\
0.593^{*}\end{aligned}$ & 0.022 & -0.058 & 0.036 & 0.632 & 2.898 \\
\hline Female literacy (\%) & -1.013 & 0.218 & -1.463 & -0.563 & $<0.001$ & 1.876 & -0.125 & 0.029 & -0.184 & -0.066 & $<0.001$ & 2.043 & -0.029 & 0.029 & -0.089 & 0.030 & 0.321 & 1.833 \\
\hline Low birth weight (\%) & 1.260 & 0.446 & 0.339 & 2.180 & 0.009 & 1.127 & 0.271 & 0.064 & 0.138 & 0.404 & $<0.001$ & 1.096 & 0.197 & 0.064 & 0.067 & 0.327 & 0.004 & 1.015 \\
\hline Skilled attendance at birth (\%) & 0.004 & 0.158 & -0.326 & 0.335 & 0.978 & 1.223 & -0.064 & 0.018 & -0.102 & -0.027 & 0.002 & 1.031 & -0.023 & 0.018 & -0.060 & 0.013 & 0.200 & 1.037 \\
\hline Intimate-partner violence (\%) & 0.247 & 0.371 & -0.521 & 1.016 & 0.511 & 2.419 & 0.012 & 0.055 & -0.101 & 0.125 & 0.828 & 2.416 & 0.075 & 0.051 & -0.029 & 0.179 & 0.152 & 2.239 \\
\hline $\begin{array}{l}\text { All-abortion hospitalisation ratio (per } \\
100 \text { live births) }\end{array}$ & -0.962 & 0.352 & -1.689 & -0.236 & 0.012 & 1.779 & -0.016 & 0.051 & -0.121 & 0.089 & 0.755 & 1.961 & 0.011 & 0.053 & -0.099 & 0.121 & 0.834 & 2.021 \\
\hline Constitutional amendment (yes) & 1.195 & 1.563 & -2.037 & 4.428 & 0.452 & 1.076 & 0.235 & 0.209 & -0.198 & 0.667 & 0.273 & 1.046 & -0.172 & 0.215 & -0.614 & 0.270 & 0.430 & 1.056 \\
\hline Abortion legislation (less permissive) & -0.226 & 1.972 & -4.327 & 3.875 & 0.910 & 1.597 & -0.053 & 0.293 & -0.663 & 0.557 & 0.858 & 1.796 & 0.060 & 0.287 & -0.534 & 0.653 & 0.837 & 1.722 \\
\hline TFR & -14.329 & 4.158 & -22.911 & -5.747 & 0.002 & 1.728 & -1.750 & 0.606 & -3.001 & -0.500 & 0.008 & 2.143 & 1.383 & 0.434 & 0.495 & 2.270 & 0.003 & 1.015 \\
\hline $\mathrm{R}^{2}$ for model & $0.714^{*}$ & & & & & & $0.666^{*}$ & & & & & & $0.335^{*}$ & & & & & \\
\hline
\end{tabular}

${ }^{*} \mathrm{p}<0.001$.iAMR, induced abortion mortality ratio; MMR, maternal mortality ratio; MMR ${ }_{\mathrm{AO}}$, MMR with abortive outcome; TFR, average total fertility rate between 2002-2011; VIF, variance inflation factor. 
Table 9 Comparison of different indicators of maternal healthcare and human development between groups of states with less and more permissive abortion legislation

\begin{tabular}{|c|c|c|c|c|}
\hline Variable & $\begin{array}{l}\text { Less permissive } \\
\text { states }(n=18)\end{array}$ & $\begin{array}{l}\text { More permissive } \\
\text { states }(n=14)\end{array}$ & Rate ratio* & p Value \\
\hline Clean watert (\%) & 91.9 & 85.6 & 1.07 & $<0.001 \ddagger$ \\
\hline Sanitationt (\%) & 91.3 & 87.0 & 1.05 & $<0.001 \ddagger$ \\
\hline Total fertility rate & 2.4 & 2.3 & $\S$ & 0.7819 \\
\hline Contraceptive use $^{\star \star}(\%)$ & 72.3 & 73.3 & 0.99 & $<0.001 \ddagger$ \\
\hline Skilled attendance at birth†† (\%) & 91.4 & 90.3 & 1.01 & $<0.001 \ddagger$ \\
\hline Low birth weight†† (\%) & 8.1 & 9.6 & 0.84 & $<0.001 \ddagger$ \\
\hline Female literacył‡ (\%) & 93.3 & 89.3 & 1.05 & $<0.001 \ddagger$ \\
\hline All-abortion hospitalisation ratiott, per 100 live births & 7.6 & 6.1 & 1.25 & $<0.001 \ddagger$ \\
\hline Intimate-partner violence $\ddagger$ (\%) & 11.1 & 11.9 & 0.93 & $<0.001 \ddagger$ \\
\hline
\end{tabular}

*Z-test rate ratio.

†Proportions were weighted using a specific denominator of exposed populations for each state.

$\ddagger Z$-test $p$ value.

§Not applicable.

It test $p$ value.

** Proportions were weighted using a specific denominator of exposed female populations in ages $15-49$ for each state.

††Proportions and ratio were weighted using a specific denominator of observed live births in each state.

‡ҒProportions were weighted using a specific denominator of exposed female populations in ages 15 and above for each state.

decreased number of children per woman without a substantial delay of motherhood, later stages of fertility reduction appear to be primarily associated with delayed motherhood. $^{30} \quad 40 \quad 63 \quad 6572 \quad 73$ The net effect of this change would be an increase in pregnancies among women above 35 years of age, which in turn increases the risk of complications and mortality from nonobstetric pre-existing medical conditions such as hypertension, diabetes, renal disease and obesity, as well as obstetric conditions such as gestational hypertension, pre-eclampsia, gestational diabetes, postpartum haemorrhage, recurrent miscarriage, caesarean section and indirect causes. ${ }^{40} 65$ 71-77 $\mathrm{A}$ recent study in Mexico showed that over $75 \%$ of maternal deaths are related to these causes. ${ }^{37}$ Considering a TFR of 2.3 for this country in 2011, a fertility paradox phenomenon may be underlying the inverse correlations between TFR and MMR or $\mathrm{MMR}_{\mathrm{AO}}$ observed in this study. Access to adequate preconception counselling and family planning programmes to promote healthy childbearing before 35 years of age may be useful for addressing the problem of an excessively delayed motherhood, in addition to preventing unplanned pregnancies.

Alternative multivariate models identified clean water and sanitation as variables influencing maternal and abortion-related mortality in Mexican states. These findings are consistent with the association of such environmental risk factors with maternal mortality. ${ }^{30} 7879$ A recent systematic review and meta-analysis proposed plausible mechanisms to explain this association: ${ }^{79}$ first, poor hygienic conditions may lead to sepsis during childbirth, one of the main causes of maternal deaths worldwide. ${ }^{78}$ Second, exposure to poor water and sanitation increases the likelihood of repeated water-borne infections, which may lead to long-term detrimental effects on the female population of fertile age. ${ }^{79}$
Considering the current disparities among Mexican states in the access to clean water and sanitation (ranging from $62.0 \%$ to 99.2\%), this study's findings highlight the potential positive impact of these basic elements of human development to continue improving maternal health in Mexico and other developing countries.

This study found that female literacy was a major variable influencing all mortality outcomes studied, explaining between $11.9 \%$ and $50.9 \%$ of the variance among Mexican states. For each 1\% increase in female literacy, decreases of 1.1 in MMR, 0.07 in $\mathrm{MMR}_{\mathrm{AO}}$, and 0.12 in iAMR per 100000 live births were estimated. The gap in female literacy among states, ranging from $77.5 \%$ to $96.5 \%$, suggests that public programmes directed at increasing women's education level may have a positive impact on maternal health in Mexico. In addition to a direct impact on maternal mortality, ${ }^{10} 30$ 80-82 women's education is correlated with other major predictors of maternal health, such as skilled attendance at birth, ${ }^{30} 8384$ access to antenatal care, ${ }^{3-5}$ fertility rate, ${ }^{10} 3085$ family planning ${ }^{86}$ and contraceptive use. ${ }^{87} 88$ Since education is likely to indicate early life circumstances and future socioeconomic outcomes, ${ }^{89-91}$ women's education level may represent an antecedent variable impacting reproductive behaviour, use of maternal health facilities and family planning programmes, and access to improved sanitation. ${ }^{30}$ Furthermore, since women's literacy can explain territorial differences in maternal mortality, predictive models of MMR considering differences in women's education level ${ }^{10}$ are likely to be more precise than models neglecting to consider education, ${ }^{12} 68$ as a recent comparative analysis suggests. ${ }^{92}$

Finally, intimate-partner violence against women over the past year was identified as an additional factor 
PRIMARY MODEL
MMR

\section{ALTERNATIVE MODELS}

Replacing Female literacy with Clean water

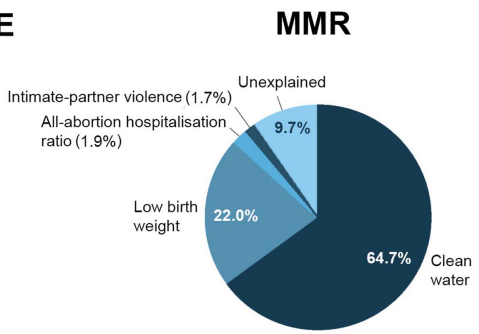

Replacing Female literacy with Sanitation
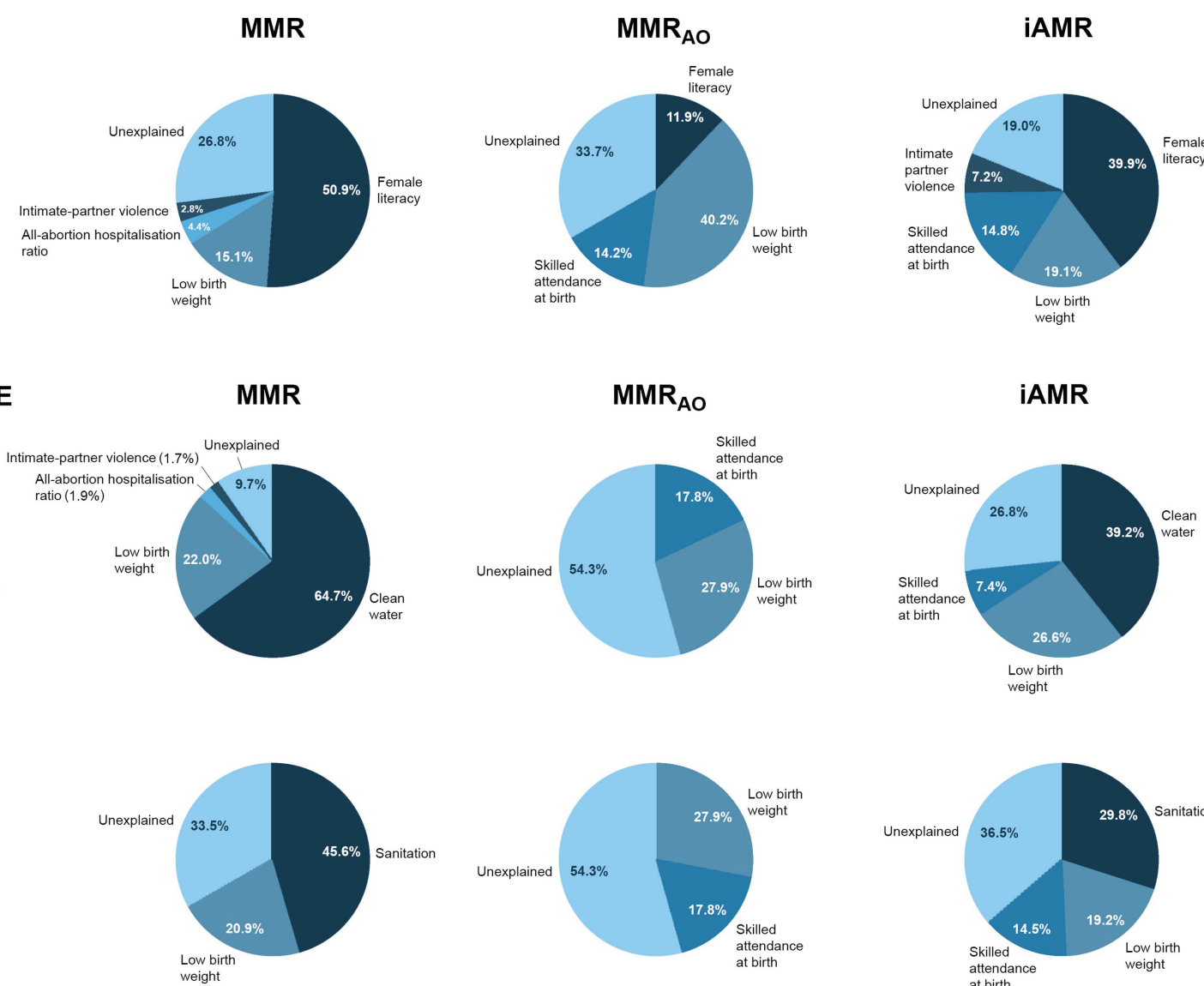

Replacing

Contraceptive use with TFR

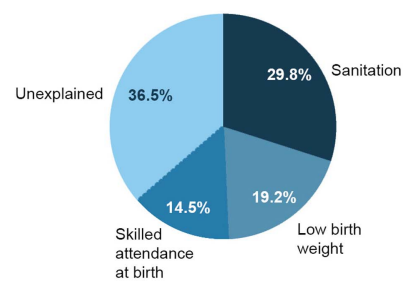

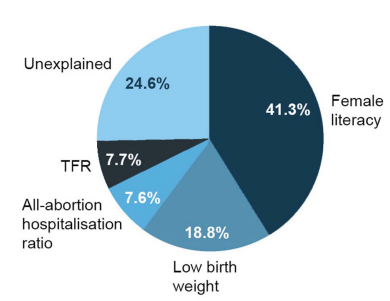
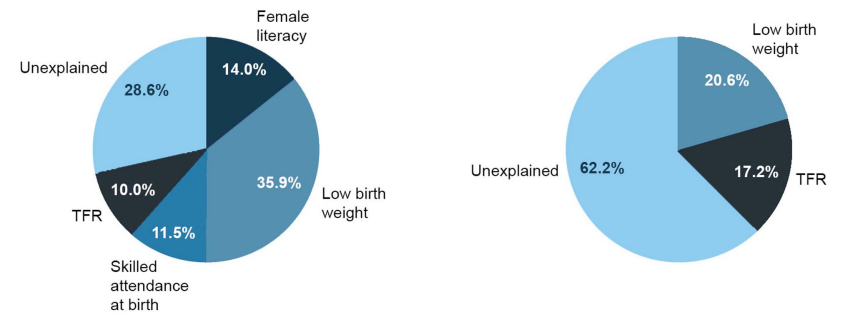

Figure 8 Proportional contribution of independent variables to observed differences in maternal mortality outcomes among Mexican states in primary and alternative multivariate regression models. IAMR, induced abortion mortality ratio; MMR, maternal mortality ratio; $\mathrm{MMR}_{\mathrm{AO}}$, MMR with abortive outcome; TFR, total fertility rate.

influencing maternal and induced abortion-related mortality. For each $1 \%$ increase in intimate-partner violence, increases of 0.8 in MMR and 0.1 in iAMR per 100000 live births were estimated, explaining $2.8 \%$ and $7.2 \%$, respectively, of the variance among Mexican states. An association between intimate-partner violence ${ }^{93} 94$ and several detrimental maternal outcomes such as antenatal haemorrhage,${ }^{95}$ vaginal bleeding, ${ }^{96}$ antenatal hospitalisation, ${ }^{96}$ caesarean section, ${ }^{96}$ preterm birth, ${ }^{96}$ miscarriages, ${ }^{97}$ pregnancy termination, ${ }^{97} \quad{ }^{98}$ repeated abortion, ${ }^{99}$ perinatal death, ${ }^{95}$ femicide ${ }^{100}$ and poor mental health outcomes, ${ }^{101}$ including suicide attempt, ${ }^{102}$ has been previously described. In addition, since sexual coercion ${ }^{103-106}$ and abuse ${ }^{93}$ have been identified as strong predictors of induced abortion, these factors may influence MMR and iAMR, which warrants further research. Recent reports suggest that detection of violence against pregnant women during prenatal visits $^{107} 108$ and subsequent interventions by skilled health professionals may improve maternal outcomes. ${ }^{109} 110$ Given the current statistics of intimatepartner violence against women observed in Mexican states (ranging from $6.3 \%$ in Oaxaca to $20.9 \%$ in the Federal District), such interventions may contribute to improved maternal health.

\section{Limitations}

Paraphrasing Geoffrey Rose, ${ }^{111}$ epidemiological research traditionally distinguishes two kinds of aetiological questions. For instance, the question "Why do some pregnant women die from abortion or gestational hypertension and others do not?" is different from "Why do some 
Box 1 Evidence-based public health interventions to improve maternal health in Mexico

Increase access to antenatal care and coverage of institutional deliveries.

- Increase number of and access to emergency obstetric units

- Expand specialised diagnostic centres and prenatal care for highrisk pregnancies, with incorporation of other medical specialties.

- Increase access to adequate preconception counselling and family planning programmes to promote healthy childbearing before 35 years of age and to prevent unplanned pregnancies.

- Strengthen public policies directed to increase the number of schooling years of the female population.

- Improve detection of violence against pregnant women during prenatal visits and intervention by skilled health professionals.

- Address disparities in human development indicators by increasing access to clean water and sanitation coverage.

populations exhibit more deaths of pregnant women because of abortion or gestational hypertension?" While the first question asks for the causes of 'cases' at the individual level, the second asks for the causes of 'incidence' at the population level; consequently, to answer these questions, different kinds of epidemiological studies are required. In this context, the examination of current abortion laws in 32 Mexican states provided an interesting natural experiment to assess whether more or less permissive legislation was associated with lower or higher incidences of maternal and abortion-related deaths, simultaneously controlling for multiple confounders at the population level. However, this study-based on aggregated data-cannot conclusively rule out the influence of different factors impacting maternal health to an individual level of analysis, and therefore an ecological fallacy ${ }^{112} 113$ should be avoided. In contrast, an individualistic fallacy, ${ }^{113}{ }^{114}$ based on the "high-risk ${ }^{111}$ approach, should also be avoided in the interpretation of these results.

A major limitation of evaluating the impact of abortion legislation in terms of permissiveness is the intrastate heterogeneity in criminal codes and the inability to randomly allocate a population of individuals to univocally defined groups, apparently making the criterion to segregate into each group somewhat arbitrary. However, after thorough exploratory analyses considering both the number and the type of legal exemptions for the criminal prosecution of abortion, only the exemption of prosecution of abortion in cases of genetic or congenital fetal malformations in their criminal codes was found to provide clear differences in mortality outcomes. In the case of Mexican states, this criminal exemption hinges on the opinion of a physician stating that there are sufficient reasons to think that such alterations would result in an individual with serious physical or mental deficiencies. ${ }^{38}$ Thus, this exemption would not contemplate criminal prosecution for an induced abortion in extreme cases of fetal malformation, such as holoprosencephaly (a failure to develop two cerebral hemispheres, lethal in utero or shortly after birth), or less extreme conditions, such as Down syndrome (trisomy of chromosome 21, characterised by survival into adulthood). In addition, it is reasonable to think that the presence or absence of this exemption may reflect different cultural values and attitudes towards abortion itself.

This study relies on official sources of data for mortality outcomes, live births and covariates. Errors such as under-reported deaths cannot be definitively ruled out. However, minimal errors are expected since 2002 because of the strengthening of the epidemiological surveillance system in that year, incorporating maternal death audits to identify misclassifications and minimising under-reporting. ${ }^{15}$ For instance, in a 2009 audit of maternal deaths conducted in Mexico identifying causes of deaths during the influenza A H1N1 epidemic, authors were able to distinguish subcategories of causes of deaths, including complications of spontaneous abortion, induced abortion and unspecified abortion. ${ }^{116} \mathrm{On}$ the other hand, instrumental bias because of different methodologies used to assess the same variable in different populations is a frequent problem in studies of multiple populations. Nevertheless, each independent variable used for this study was compiled with a single instrument applied in all Mexican states, making instrumental bias unlikely.

A problem in countries with legal restrictions for pregnancy termination is the difficulty of obtaining counts and rates of illegal abortions. Nevertheless, the problem of under-reporting of illegal abortions does not translate necessarily to under-reporting of deaths from complications of illegal procedures when specific codes of the ICD-10 are in use. Recent studies in Mexico ${ }^{37}$ and Chile ${ }^{117}$ suggest that both mortality and morbidity from complications of illegal abortions, or abortions without a known cause are registered using specific codes O05, $\mathrm{O} 06$ and $\mathrm{O} 07$ to differentiate them from complications of other types of abortions with a well-known cause. Consequently, these specific codes were considered for the construction of iAMR in this study. Another matter for concern is the possibility of misreporting or misclassification of deaths from induced abortion as deaths for other causes, for example, haemorrhage or sepsis. However, in Mexico, this seems unlikely because of the maternal mortality audit discussed above and the parallel decreasing trend in overall maternal mortality observed in this study. For instance, deaths from haemorrhage have decreased by $17 \%$ between $2002 \quad(10.6$ deaths per 100000 live births) and 2011 (8.8/100 000 live births). In addition, there is no reason to misreport deaths from a suspected illegal abortion considering the use of ICD10 codes O05, O06 and O07. Thus, iAMR appears to be an indicator that provides a reasonable method to circumvent the problem of under-reporting of maternal deaths from complications of illegal procedures in subsequent epidemiological studies in Latin America. 
Finally, although most variables, including those for abortion legislation, showed significant correlations with maternal mortality outcomes in Mexico, this study emphasises the importance of multivariate analyses correcting for multicollinearity between covariates and the presence of outliers on mortality outcomes. For instance, since it is not possible to completely separate statistical effect sizes of highly correlated terms in multiple regression equations, separate alternative analyses are required. In addition to seeking unbiased effect sizes for significant predictors, any statistical association requires a plausible mechanism before making causal inferences at the population level.

\section{CONCLUSION}

This population-based natural experiment, using virtually complete official vital statistics of live births and maternal deaths in 32 Mexican states between 2002 and 2011, showed that maternal and abortion-related mortality ratios were lower in states with less permissive abortion legislation compared with states with more permissive legislation. Nevertheless, the observed differences between populations were not attributable to abortion legislation by itself. In fact, exhaustive multivariate analyses showed that these differences were largely explained by other factors such as women's literacy, maternal healthcare, water, sanitation, fertility rate and violence against women. These findings suggest that favourably addressing disparities in these factors may facilitate an epidemiological transition towards low maternal mortality rates in developing countries during the post-MDG agenda.

\author{
Author affiliations \\ ${ }^{1}$ Division of Epidemiology, MELISA Institute, Concepción, Chile \\ ${ }^{2}$ Department of Obstetrics and Gynecology, Duke University Medical Center, \\ Durham, USA \\ ${ }^{3}$ Instituto de Investigaciones Sociales, Universidad Nacional Autónoma de \\ México, Av Universidad 3000, Copilco Universidad, Ciudad de México, Mexico \\ ${ }^{4}$ Division of Public Health, Department of Family and Preventive Medicine, \\ University of Utah School of Medicine, Salt Lake City, USA \\ ${ }^{5}$ Coordinación de Investigación, Facultad de Ciencias de la Salud, Universidad \\ Anáhuac, Estado de México, Mexico \\ ${ }^{6}$ Department of Obstetrics and Gynecology, West Virginia University, \\ Morgantown, USA \\ ${ }^{7}$ Department of Obstetrics and Gynecology, University of North Carolina- \\ Chapel Hill, Chapel Hill, USA \\ ${ }^{8}$ Center for Women's Health Research, University of North Carolina School of \\ Medicine, Chapel Hill, USA
}

Acknowledgements This study was conducted on behalf of the Research Endeavour on Abortion in Latin America (REAL), which is an independent collaborative research project currently conducted by researchers from the following institutions: Department of Obstetrics and Gynecology, Duke University Medical Center; Center for Women's Health Research, University of North Carolina Chapel Hill; Instituto de Investigaciones Sociales, Universidad Nacional Autónoma de México (México); Department of Family and Preventive Medicine, University of Utah School of Medicine; Coordinación de Investigación, Facultad de Ciencias de la Salud, Universidad Anáhuac, Department of Obstetrics and Gynecology, West Virginia University; and MELISA Institute. The authors are indebted to the reviewers for their valuable suggestions to improve our manuscript.
Contributors EK was the leading author. EK and MC conceptualised the study. EK, MC, FP, JS and SH contributed to the study design. MB, FP, SH and $S G$ were directly involved in the acquisition of data. SG reviewed abortion legislation for each state with the advice of FP, SH and PA. EK, MC, PA and MB had the main responsibility for data analysis and FP, JS, SH, BC, SG and JT had full access to data, including results of statistical analyses. EK, MC, PA, MB and SG drafted the manuscript, and FP, JS, SH, BC and JT reviewed and commented on drafts and approved the final manuscript. EK is the guarantor of the study, accepts full responsibility for the research, had access to the data, and controlled the decision to publish.

Funding This study was partially funded by research grants UNC102010 from the Center for Women's Health Research at UNC (http://cwhr.unc.edu/) and MEL1040613 from the FISAR foundation (http://www.fisarchile.org).

\section{Competing interests None.}

Provenance and peer review Not commissioned; externally peer reviewed.

Data sharing statement Extra data can be accessed via the Dryad data repository at http://datadryad.org/ with the doi:10.5061/dryad.d6b23

Open Access This is an Open Access article distributed in accordance with the Creative Commons Attribution Non Commercial (CC BY-NC 4.0) license, which permits others to distribute, remix, adapt, build upon this work noncommercially, and license their derivative works on different terms, provided the original work is properly cited and the use is non-commercial. See: http:// creativecommons.org/licenses/by-nc/4.0/

\section{REFERENCES}

1. United Nations. Resolution adopted by the General Assembly: United Nations Millennium Declaration. 2000;55/2:1-9. http://www. un.org/en/ga/search/view_doc.asp?symbol=A/RES/55/2 (accessed 3 Apr 2014).

2. Sachs JD, McArthur JW. The Millennium Project: a plan for meeting the Millennium Development Goals. Lancet 2005;365:347-53.

3. Adam T, Lim SS, Mehta S, et al. Cost effectiveness analysis of strategies for maternal and neonatal health in developing countries. BMJ 2005;331:1107

4. Rööst M, Altamirano VC, Liljestrand J, et al. Does antenatal care facilitate utilization of emergency obstetric care? A case-referent study of near-miss morbidity in Bolivia. Acta Obstet Gynecol Scand 2010;89:335-42.

5. Simkhada B, Teijlingen ERV, Porter M, et al. Factors affecting the utilization of antenatal care in developing countries: systematic review of the literature. J Adv Nurs 2008;61:244-60.

6. Mbonye AK, Asimwe JB. Factors associated with skilled attendance at delivery in Uganda: results from a national health facility survey. Int J Adolesc Med Health 2010;22:249-55.

7. Kayongo M, Esquiche E, Luna MR, et al. Strengthening emergency obstetric care in Ayacucho, Peru. Int J Gynaecol Obstet 2006;92:299-307.

8. Wilson A, Gallos ID, Plana N, et al. Effectiveness of strategies incorporating training and support of traditional birth attendants on perinatal and maternal mortality: meta-analysis. BMJ 2011;343: d7102.

9. Adegoke A, van den Broek N. Skilled birth attendance-lessons learnt. BJOG 2009;116(Suppl 1):33-40.

10. Hogan MC, Foreman KJ, Naghavi M, et al. Maternal mortality for 181 countries, 1980-2008: a systematic analysis of progress towards Millennium Development Goal 5. Lancet 2010;375:1609-23.

11. Lozano $\mathrm{R}$, Wang $\mathrm{H}$, Foreman $\mathrm{KJ}$, et al. Progress towards Millennium Development Goals 4 and 5 on maternal and child mortality: an updated systematic analysis. Lancet 2011;378:1139-65.

12. WHO. Trends in maternal mortality 1990-2010. WHO, UNICEF, UNFPA and The World Bank estimates: World Health Organization, Geneva 2012:1-59. http://www.unfpa.org/webdav/site/global/ shared/documents/publications/2012/Trends_in_maternal mortality A4-1.pdf (accessed 3 Apr 2014).

13. Bryce J, Black RE, Victora CG. Millennium Development Goals 4 and 5: progress and challenges. BMC Med 2013;11:225. doi:10.1186/1741-7015-11-225

14. Lomazzi M, Borisch B, Laaser U. The Millennium Development Goals: experiences, achievements and what's next. Glob Health Action 2014;7:23695. 
15. Craig P, Cooper C, Gunnell D, et al. Using natural experiments to evaluate population health interventions: new Medical Research Council guidance. J Epidemiol Community Health 2012;66:1182-6.

16. Petticrew M, Cummins S, Ferrell C, et al. Natural experiments: an underused tool for public health? Public Health 2005;119:751-7.

17. Ross L, Simkhada P, Smith WC. Evaluating effectiveness of complex interventions aimed at reducing maternal mortality in developing countries. J Public Health (Oxf) 2005;27:331-7.

18. Rolnick JA, Vorhies JS. Legal restrictions and complications of abortion: insights from data on complication rates in the United States. J Public Health Policy 2012;33:348-62.

19. Singh K, Ratnam SS. The influence of abortion legislation on maternal mortality. Int J Gynaecol Obstet 1998;63(Suppl 1): S123-9.

20. Brown H. Abortion round the world. BMJ 2007:335:1018-19.

21. Grimes DA, Benson J, Singh S, et al. Unsafe abortion: the preventable pandemic. Lancet 2006;368:1908-19.

22. Kulczycki A. Abortion in Latin America: changes in practice, growing conflict, and recent policy developments. Stud Fam Plann 2011;42:199-220.

23. Calhoun B. The maternal mortality myth in the context of legalized abortion. Linacre Q 2013;80:264-76.

24. Koch E. Impact of reproductive loss on maternal mortality: the Chilean natural experiment. Linacre Q 2013;80:151-60.

25. Thorp JM. Public health impact of legal termination of pregnancy in the US: 40 Years Later. Scientifica (Cairo) 2012;2012:1-16.

26. Leiva R. Illegal abortion in El Salvador: no evidence of increase maternal mortality. BMJ Online [eLetter]. 2007. http://www.bmj.com/ rapid-response/2011/11/01/illegal-abortion-el-salvador-no-evidenceincrease-maternal-mortality

27. Koch E, Aracena P, Bravo M, et al. Methodological flaws on abortion estimates for Latin America: authors' reply to Singh and Bankole. Ginecol Obstet Mex 2012;80:740-7.

28. Calhoun BC, Thorp JM, Carroll PS. Maternal and neonatal health and abortion: 40-year trends in Great Britain and Ireland. J Am Phys Surg 2013;18:42-6.

29. Leiva R. Maternal mortality and abortion. Lancet 2010;376:515.

30. Koch E, Thorp J, Bravo M, et al. Women's education level, maternal health facilities, abortion legislation and maternal deaths: a natural experiment in Chile from 1957 to 2007. PLoS ONE 2012;7:e36613.

31. World Health Organization, Regional Office for Europe. Highlights on Health in Poland 2001:1-37. http://ec.europa.eu/health/ph projects/1999/monitoring/poland_en.pdf (accessed 3 Apr 2014).

32. Knaul FM, González-Pier E, Gómez-Dantés O, et al. The quest for universal health coverage: achieving social protection for all in Mexico. Lancet 2012;380:1259-79.

33. Dirección General de Información en Salud (DGIS). Base de datos de defunciones maternas 2002-2011. [online]: Sistema Nacional de Información en Salud (SINAIS). [México]: Secretaría de Salud. http://www.sinais.salud.gob.mx/basesdedatos/defunciones.html (accessed 13 Feb 2014).

34. Instituto Nacional de Estadística y Geografía (INEGI). http://www. inegi.org. $\mathrm{mx} / \mathrm{sistemas/olap/proyectos/bd/consulta.asp?p=11092}$ (accessed 13 Feb 2014).

35. Dirección General de Información en Salud (DGIS). Manual de búsqueda intencionada y reclasificación de muertes maternas. http://www.dgis.salud.gob.mx/descargas/pdf/Manual_BIRMM_v14n. pdf (accessed 3 Apr 2014)

36. WHO. International statistical classification of diseases and related health problems. 2011:1-201. http://www.who.int/classifications/icd/ ICD10Volume2_en_2010.pdf (accessed 3 Apr 2014).

37. Koch E, Aracena P, Gatica S, et al. Fundamental discrepancies in abortion estimates and abortion-related mortality: a reevaluation of recent studies in Mexico with special reference to the International Classification of Diseases. Int J Women Health 2012;4:613-23.

38. Legislación en el Ámbito Estatal y del Distrito Federal. Orden Jurídico Nacional. http://www.ordenjuridico.gob.mx/index.php (accessed 3 Apr 2014)

39. Administración Pública del Distrito Federal. Decreto por el que se reforma el Código Penal para el Distrito Federal y se adiciona la Ley de Salud para el Distrito Federal. Gac Oficial Distrito Fed 2007;70:2-3

40. Koch E, Bogado M, Araya F, et al. Impact of parity on anthropometric measures of obesity controlling by multiple confounders: a cross-sectional study in Chilean women. $J$ Epidemiol Community Health 2008;62:461-70.

41. Gissler M, Fronteira I, Jahn A, et al. Terminations of pregnancy in the European Union. BJOG 2012;119:324-32.

42. Schiavon R, Troncoso E, Polo G. Analysis of maternal and abortion-related mortality in Mexico over the last two decades,
1990-2008. Int J Gynaecol Obstet 2012;118(Suppl 2):S78-86. doi:10.1016/S0020-7292(12)60004-6

43. Denisov BP, Sakevich VI, Jasilioniene A. Divergent trends in abortion and birth control practices in Belarus, Russia and Ukraine. PLOS ONE 2012;7:e49986.

44. Zhu WX, Lu L, Hesketh T. China's excess males, sex selective abortion, and one child policy: analysis of data from 2005 national intercensus survey. BMJ 2009;338:b1211.

45. Harries J, Cooper D, Strebel A, et al. Conscientious objection and its impact on abortion service provision in South Africa: a qualitative study. Reprod Health 2014;11:16.

46. Aniteye P, Mayhew SH. Shaping legal abortion provision in Ghana: using policy theory to understand provider-related obstacles to policy implementation. Health Res Policy Syst 2013;11:23.

47. Culwell KR, Hurwitz M. Addressing barriers to safe abortion. Int J Gynaecol Obstet 2013;121(Suppl 1):S16-9.

48. Shryock HS, Siegel JS. Internal migration and short-distance mobility. In: Larmon EA., ed. The methods and materials of demography. vol 2. Washington DC: U.S. Bureau of the Census, 1980:616-72.

49. WHO. Skilled birth attendants. http://www.who.int/maternal_child adolescent/topics/maternal/skilled_birth/en/ (accessed 4 Apr 2014).

50. Alvarez JL, Gil R, Hernández V, et al. Factors associated with maternal mortality in Sub-Saharan Africa: an ecological study. BMC Public Health 2009;9:462.

51. Sinha S, Upadhyay RP, Tripathy JP, et al. Does utilization of antenatal care result in an institutional delivery? Findings of a record-based study in urban Chandigarh. J Trop Pediatr 2013:59:220-2.

52. Vasquez DN, Estenssoro E, Canales HS, et al. Clinical characteristics and outcomes of obstetric patients requiring ICU admission. Chest 2007;131:718-24.

53. Donati $\mathrm{S}$, Senatore $\mathrm{S}$, Ronconi A, et al. Obstetric near-miss cases among women admitted to intensive care units in Italy. Acta Obstet Gynecol Scand 2012;91:452-7.

54. Cleland K, Creinin MD, Nucatola D, et al. Significant adverse events and outcomes after medical abortion. Obstet Gynecol 2013;121:166-71.

55. Koch E, Bravo M, Gatica S, et al. Overestimation of induced abortion in Colombia and other Latin American countries. Ginecol Obstet Mex 2012;80:360-72.

56. Adler AJ, Filippi V, Thomas SL, et al. Quantifying the global burden of morbidity due to unsafe abortion: magnitude in hospital-based studies and methodological issues. Int J Gynaecol Obstet 2012;118:S65-77.

57. Ranji A. Induced abortion in Iran: prevalence, reasons, and consequences. J Midwifery Womens Health 2012;57:482-8.

58. Valero de Bernabé J, Soriano T, Albaladejo R, et al. Risk factors for low birth weight: a review. Eur J Obstet Gynecol Reprod Biol 2004:116:3-15.

59. Bánhidy F, Acs N, Puhó EH, et al. Association of very high Hungarian rate of preterm births with cervical incompetence in pregnant women. Cent Eur J Public Health 2010;18:8-15.

60. Scholten BL, Page-Christiaens GCML, Franx A, et al. The influence of pregnancy termination on the outcome of subsequent pregnancies: a retrospective cohort study. BMJ Open 2013;3: $1-7$.

61. Shah PS, Zao J.; Knowledge Synthesis Group of Determinants of preterm/LBW births. Induced termination of pregnancy and low birthweight and preterm birth: a systematic review and meta-analyses. BJOG 2009;116:1425-42.

62. Brown JS, Adera T, Masho SW. Previous abortion and the risk of low birth weight and preterm births. J Epidemiol Community Health 2008;62:16-22.

63. Nelson-Piercy C, Mackillop L, Williams DJ, et al. Maternal mortality in the UK and the need for obstetric physicians. BMJ 2011;343: d4993.

64. Rosenfield A, Min CJ, Freedman LP. Making motherhood safe in developing countries. N Engl J Med 2007;356:1395-7.

65. Donoso SE, Carvajal C JA. [The change in the epidemiological profile of maternal mortality in Chile will hinder the fulfillment of the Millennium 5th goal]. Rev Med Chil 2012;140:1253-62.

66. Jain AK. Measuring the effect of fertility decline on the maternal mortality ratio. Stud Fam Plann 2011;42:247-60.

67. Winikoff B, Sullivan M. Assessing the role of family planning in reducing maternal mortality. Stud Fam Plann 1987;18:128-43.

68. Ahmed S, Li Q, Liu L, et al. Maternal deaths averted by contraceptive use: an analysis of 172 countries. Lancet 2012;380:111-25.

69. WHO. Unsafe abortion. Global and regional estimates of the incidence of unsafe abortion and associated mortality in 2008. 
2011:1-56. http://whqlibdoc.who.int/publications/2011/ 9789241501118 eng.pdf?ua=1 (accessed 4 Apr 2014)

70. Stover J, Ross J. How increased contraceptive use has reduced maternal mortality. Matern Child Health J 2010;14:687-95.

71. Kurjak A, Carrera JM. Declining fertility in the developed world and high maternal mortality in developing countries-how do we respond? J Perinat Med 2005;33:95-9.

72. Luque Fernandez MA, Cavanillas $A B$, Dramaix-Wilmet $M$, et al. Increase in maternal mortality associated with change in the reproductive pattern in Spain: 1996-2005. J Epidemiol Community Health 2009;63:433-8.

73. López PO, Bréart G. Sociodemographic characteristics of mother's population and risk of preterm birth in Chile. Reprod Health 2013;10:26.

74. Cleary-Goldman J, Malone FD, Vidaver J, et al. Impact of maternal age on obstetric outcome. Obstet Gynecol 2005;105:983-90.

75. Kenny LC, Lavender T, McNamee R, et al. Advanced maternal age and adverse pregnancy outcome: evidence from a large contemporary cohort. PLOS ONE 2013;8:e56583.

76. Oboro VO, Dare FO. Pregnancy outcome in nulliparous women aged 35 or older. West Afr J Med 2006;25:65-8.

77. Ziadeh SM. Maternal and perinatal outcome in nulliparous women aged 35 and older. Gynecol Obstet Invest 2002;54:6-10.

78. WHO. Health through safe drinking water and basic sanitation. http://www.who.int/water_sanitation_health/mdg1/en/ (accessed 3 Apr 2014)

79. Benova L, Cumming O, Campbell OM. Systematic review and meta-analysis: association between water and sanitation environment and maternal mortality. Trop Med Int Health 2014;19:368-87.

80. Karlsen S, Say L, Souza J-P, et al. The relationship between maternal education and mortality among women giving birth in health care institutions: analysis of the cross sectional WHO Global Survey on Maternal and Perinatal Health. BMC Public Health 2011:11:606.

81. McAlister C, Baskett TF. Female education and maternal mortality: a worldwide survey. J Obstet Gynaecol Can 2006;28:983-90.

82. Pillai VK, Maleku A, Wei FH. Maternal mortality and female literacy rates in developing countries during 1970-2000: a latent growth curve analysis. Int J Popul Res 2013;2013:1-11.

83. Robinson $\mathrm{JJ}$, Wharrad $\mathrm{H}$. The relationship between attendance at birth and maternal mortality rates: an exploration of United Nations' data sets including the ratios of physicians and nurses to population, GNP per capita and female literacy. J Adv Nurs 2001;34:445-55.

84. Gabrysch S, Campbell OMR. Still too far to walk: literature review of the determinants of delivery service use. BMC Pregnancy Childbirth 2009;9:34.

85. Adhikari R. Demographic, socio-economic, and cultural factors affecting fertility differentials in Nepal. BMC Pregnancy Childbirth 2010;10:19.

86. Jiang L, Hardee K. Women's education, family planning, or both? Application of multistate demographic projections in India. Int $J$ Popul Res 2014;940509:1-9.

87. Kozinszky Z, Sikovanyecz J, Devosa I, et al. Determinants of emergency contraceptive use after unprotected intercourse: who seeks emergency contraception and who seeks abortion? Acta Obstet Gynecol Scand 2012;91:959-64.

88. Nketiah-Amponsah E, Arthur E, Abuosi A. Correlates of contraceptive use among Ghanaian women of reproductive age (15-49 years). Afr J Reprod Health 2012;16:154-69.

89. Singh-Manoux A. Commentary: modelling multiple pathways to explain social inequalities in health and mortality. Int $\mathrm{J}$ Epidemiol 2005;34:638-9.

90. Koch E, Romero T, Romero CX, et al. Early life and adult socioeconomic influences on mortality risk: preliminary report of a 'pauper rich' paradox in a Chilean adult cohort. Ann Epidemiol 2010;20:487-92.

91. Koch E, Romero T, Romero CX, et al. Impact of education, income and chronic disease risk factors on mortality of adults: does 'a pauper-rich paradox' exist in Latin American societies? Public Health 2010;124:39-48.

92. Koch E, Calhoun B, Aracena P, et al. Women's education level, contraceptive use and maternal mortality estimates. Public Health 2014;128:384-7.

93. Pallitto CC, Garcia-Moreno C, Jansen HAFM, et al. Intimate partner violence, abortion, and unintended pregnancy: results from the
WHO Multi-country Study on Women's Health and Domestic Violence. Int J Gynecol Obstet 2013;120:3-9.

94. WHO. Intimate partner violence during pregnancy. 2011:1-4. http:// whqlibdoc.who.int/hq/2011/WHO RHR 11.35 eng.pdf (accessed 4 Apr 2014).

95. Janssen PA, Holt VL, Sugg NK, et al. Intimate partner violence and adverse pregnancy outcomes: a population-based study. Am J Obstet Gynecol 2003;188:1341-7.

96. Hassan M, Kashanian M, Roohi M, et al. Maternal outcomes of intimate partner violence during pregnancy: study in Iran. Public Health 2014;128:410-15.

97. Stöckl H, Filippi V, Watts C, et al. Induced abortion, pregnancy loss and intimate partner violence in Tanzania: a population based study. BMC Pregnancy Childbirth 2012;12:12.

98. Antai D, Adaji S. Community-level influences on women's experience of intimate partner violence and terminated pregnancy in Nigeria: a multilevel analysis. BMC Pregnancy Childbirth 2012;12:128

99. Fisher WA, Singh SS, Shuper PA, et al. Characteristics of women undergoing repeat induced abortion. CMAJ 2005;172: $637-41$

100. McFarlane J, Campbell JC, Sharps P, et al. Abuse during pregnancy and femicide: urgent implications for women's health. Obstet Gynecol 2002;100:27-36.

101. Kendall-Tackett KA. Violence against women and the perinatal period: the impact of lifetime violence and abuse on pregnancy, postpartum, and breastfeeding. Trauma Violence Abuse 2007;8:344-53.

102. Devries K, Watts C, Yoshihama M, et al. Violence against women is strongly associated with suicide attempts: evidence from the WHO multi-country study on women's health and domestic violence against women. Soc Sci Med 2011;73:79-86.

103. Pilecco FB, Knauth DR, Vigo Á. [Sexual coercion and abortion: a context of vulnerability among young women]. Cad Saude Publica 2011;27:427-39.

104. Silverman JG, Decker MR, McCauley HL, et al. Male perpetration of intimate partner violence and involvement in abortions and abortion-related conflict. Am J Public Health 2010;100: 1415-17.

105. Polis CB, Lutalo T, Wawer M, et al. Coerced sexual debut and lifetime abortion attempts among women in Rakai, Uganda. Int $J$ Gynecol Obstet 2009;104:105-9.

106. Yimin C, Shouqing L, Arzhu Q, et al. Sexual coercion among adolescent women seeking abortion in China. $J$ Adolesc Health 2002;31:482-6.

107. Bacchus L, Mezey G, Bewley S, et al. Prevalence of domestic violence when midwives routinely enquire in pregnancy. BJOG 2004:111:441-5.

108. Chamberlain L, Perham-Hester KA. Physicians' screening practices for female partner abuse during prenatal visits. Matern Child Health $J$ 2000;4:141-8.

109. McFarlane J, Soeken K, Wiist W. An evaluation of interventions to decrease intimate partner violence to pregnant women. Public Health Nurs 2000;17:443-51.

110. Parker B, McFarlane J, Soeken $\mathrm{K}$, et al. Testing an intervention to prevent further abuse to pregnant women. Res Nurs Health 1999;22:59-66.

111. Rose G. Sick individuals and sick populations. Int J Epidemiol 1985;14:32-8

112. Greenland S, Robins J. Invited commentary: ecologic studiesbiases, misconceptions, and counterexamples. Am J Epidemiol 1994;139:747-60.

113. Koch E, Otarola A, Kirschbaum A. A landmark for popperian epidemiology: refutation of the randomised Aldactone evaluation study. J Epidemiol Community Health 2005;59: 1000-6.

114. Pearce N. The ecological fallacy strikes back. J Epidemiol Community Health 2000;54:326-7.

115. Lozano-Ascencio R. [ls it possible to continue the improvement of death causes registries in Mexico?]. Gac Med Mex 2008; 144:525-33.

116. Fajardo-Dolci G, Meljem-Moctezuma J, Vicente-Gonzalez E, et al. [Analysis of maternal deaths in Mexico occurred during 2009]. Rev Med Inst Mex Seguro Soc 2013;51:486-95.

117. Koch E. Epidemiology of abortion and its prevention in Chile [Epidemiología de aborto y su prevención en Chile]. Rev Chil Obstet Ginecol 2014;79:351-60. 